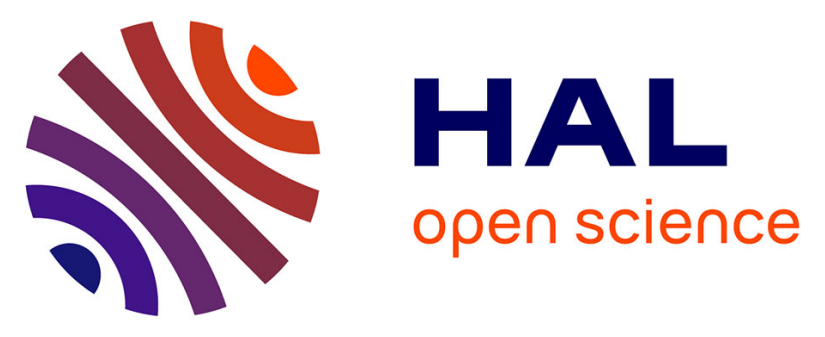

\title{
Simple Synthetic Molecular Hydrogels from Self- Assembling Alkylgalactonamides as Scaffold for 3D Neuronal Cell Growth
}

Anaïs Chalard, Laurence Vaysse, Pierre Joseph, Laurent Malaquin, Sandrine Assié-Souleille, Barbara Lonetti, Jean-Christophe Sol, Isabelle Loubinoux, Juliette Fitremann

\section{To cite this version:}

Anaïs Chalard, Laurence Vaysse, Pierre Joseph, Laurent Malaquin, Sandrine Assié-Souleille, et al.. Simple Synthetic Molecular Hydrogels from Self- Assembling Alkylgalactonamides as Scaffold for 3D Neuronal Cell Growth. ACS Applied Materials \& Interfaces, 2018, 10 (20), pp.17004 - 17017. 10.1021/acsami.8b01365 . hal-01810656

\section{HAL Id: hal-01810656 https://hal.laas.fr/hal-01810656}

Submitted on 8 Jun 2018

HAL is a multi-disciplinary open access archive for the deposit and dissemination of scientific research documents, whether they are published or not. The documents may come from teaching and research institutions in France or abroad, or from public or private research centers.
L'archive ouverte pluridisciplinaire HAL, est destinée au dépôt et à la diffusion de documents scientifiques de niveau recherche, publiés ou non, émanant des établissements d'enseignement et de recherche français ou étrangers, des laboratoires publics ou privés. 


\title{
Simple Synthetic Molecular Hydrogels from Self- Assembling Alkylgalactonamides as Scaffold for 3D Neuronal Cell Growth
}

\author{
Anaïs Chalard ${ }^{\mathrm{a}, \mathrm{b}, \mathrm{c}}$, Laurence Vaysse ${ }^{\mathrm{b}}$, Pierre Joseph ${ }^{c}$, Laurent Malaquin ${ }^{c}$, Sandrine Souleille ${ }^{c}$, Barbara \\ Lonetti $^{a}$, Jean-Christophe Sol ${ }^{b, d}$, Isabelle Loubinoux ${ }^{b}$, Juliette Fitremann ${ }^{a *}$ \\ Affiliations: \\ a IMRCP, Université de Toulouse, CNRS, Bat 2R1, 118 Route de Narbonne, 31062 Toulouse \\ Cedex 9, France. \\ b TONIC, Toulouse Neurolmaging Center, Université de Toulouse, Inserm, UPS, France. \\ c LAAS-CNRS, Université de Toulouse, CNRS, UPS, Toulouse, France \\ d Centre Hospitalier Universitaire de Toulouse; Pôle Neurosciences; CHU Toulouse, France \\ corresponding author: fitremann@chimie.ups-tlse.fr
}

Keywords: biomaterial, supramolecular gel, LMWG, self-assembly, 3D cell culture, neuron, adult human neural stem cells, hNSC.

\section{Abstract}

In this work, we demonstrated that the hydrogel obtained from a very simple and single synthetic molecule, $\mathrm{N}$-heptyl-galactonamide was a suitable scaffold for the growth of neuronal cells in 3D. We evidenced by confocal microscopy the presence of the cells into the gel up to a depth of around 200 $\mu \mathrm{m}$, demonstrating that the latter was permissive to cell growth and enabled a true 3D colonization and organization. It also supported successfully the differentiation of adult human neuronal stem cells (hNSCs) into both glial and neuronal cells and the development of a really dense neurofilament network. So the gel appears to be a good candidate for neural tissue regeneration. In contrast with other molecular gels described for cell culture, the molecule can be obtained at the gram scale by a one-step reaction. The resulting gel is very soft, a quality in accordance with the aim of growing neuronal cells, that requires low modulus substrates similar to the brain. But because of its fragility, specific procedures had to be implemented for its preparation and for cell labeling and confocal microscopy observations. Notably, the implementation of a controlled slow cooling of the gel solution was needed to get a very soft but nevertheless cohesive gel. In these conditions, very wide straight and long micrometric fibers were formed, held together by a second network of flexible narrower nanometric fibers. The two kinds of fibers guided the neurite and glial cell growth in a different way. We also underlined the importance of a tiny difference in the molecular structure on the gel performances: parent molecules, differing by a one-carbon increment in the alkyl chain length, $\mathrm{N}$-hexyl-galactonamide and $\mathrm{N}$-octyl-galactonamide, were not as good as $\mathrm{N}$-heptylgalactonamide. Their differences were analysed in terms of gel fibers morphology, mechanical properties, solubility, chain parity and cell growth. 


\section{Introduction}

This last decade, organoid and three-dimensional (3D) culture systems have opened the way of a new area of biomedical research. Three-dimensional cultures have proven very useful to expand human tissues for basic research and clinical applications. Compared with their two-dimensional counterparts, these systems provide a more physiologically relevant environment for cell growth and function. They represent more robust in vitro models to study normal or pathological conditions and can be used for drug screening ${ }^{1-3}$. They could be particularly useful in the context of neurodegenerative and neurological disorder studies where animal models are not really relevant, hindering the development of new therapies. Three-dimensional scaffolds mimicking tissue's specific microarchitectures can also be used in vivo in biotherapy strategy for tissue reconstruction. For all these reasons finding optimal scaffolds notably for neural 3D-cell culture remains one of the most challenging topics in tissue engineering ${ }^{4}$.

Most scaffolds for cell culture, including for neuronal cell cultures, are based on natural proteins (e.g collagen) or natural polysaccharides (e.g. hyaluronic acid) of the extracellular matrix ${ }^{5,6}$. More particularly many studies are using Type-I Collagen or Matrigel ${ }^{4,7-9}$. In the case of collagen, composites with a more permissive additive such as peptide hydrogels ${ }^{7,10}$ or silk protein ${ }^{11}$ are designed in order to improve the neurite outgrowth and the cell three-dimensional network formation compared with collagen-only scaffolds. In the case of Matrigel $^{9}$, the development of a relevant neuronal cell culture model of Alzheimer disease in 3D, with a robust $\beta$-amyloid-plaque formation has been shown recently using Matrigel ${ }^{12,13}$. The formation of an organoid mimicking the cerebral region was also demonstrated in Matrigel ${ }^{14}$. However, the variability of such biologically derived matrices cause sometimes non-reproducible experimental results that may compromise their use in clinic for tissue regeneration strategies. The origin of Matrigel also makes it unsuitable for clinical uses. For this reason, synthetic peptide scaffolds (e.g. Puramatrix) are also emerging for neuronal cell culture applications ${ }^{10,15-17}$. Besides, synthetic polymers have the advantage of a higher control of the origin composition and purity and few of them are currently developed today for nervous system regeneration ${ }^{8,18,19}$. They also have some limitations, such as possible inflammatory response or a limited penetration of the cells in 3D. To modulate their bioactivity and enhance cell adhesion, growth or differentiation, several strategies can be used, notably by the association with peptides such as RGD or IKVAV, derived from laminin. In the same way, different strategies are used to improve their 3D permeability to cells for example by the introduction of porogens or by setting up a well-controlled building of the scaffold by electrospinning or 3D-printing ${ }^{19-21}$. Despite this progress, synthetic matrices fitting all the requirements in terms of purity, reproducibility, processing, permeability to cells in $3 \mathrm{D}$, functionalization, degradation and mechanical properties are still needed.

In fact, even though hydrogels are among the best materials for 3D tissue engineering, whatever their origin natural or synthetic, they do not always provide the right conditions for inducing a three dimensional cell growth similar to what is observed in vivo. The criteria for a convenient 3D growth are based on the cell penetration, but also on the cell morphology, organization and functionality. In gels, the penetration of the cells in depth is not so straightforward. It depends on the network density and in many cases, the cells stay and grow only at the surface or close to their seeding place. Finding adequate matrices for $3 \mathrm{D}$ cell spreading to obtain homogenous tissue construction throughout the scaffold with nutriments access and without hypoxia troubles for long-term cultures remains thus a key point. In addition, cellular growth is not only influenced by chemical and biological cues: physical cues play a major role in stem cell fate determination and tissue organization. More especially, the mechanical properties must be considered to select the good 
scaffold in accordance with the cell type and the target tissue ${ }^{22-26}$. For neurons, very soft matrices are required, as soft as the brain, which modulus is in the range of 0.5 to $2.5 \mathrm{kPa}{ }^{27}$.

In relation to 3D cell culture, another point deserves attention, related to imaging. Actually, most of the current protocols are adapted for a one-cell thickness. For very soft gels, the application of long procedures involving numerous washings are often deleterious. In this work, these issues had to be addressed, in order to demonstrate the 3D colonization within very fragile gels adapted to the neuronal cell growth.

New families of synthetic hydrogels for cell culture have emerged recently in the field of low molecular weight supramolecular (or simply "molecular") gelators (LMWG). These soft materials are not based on polymers but on the self-assembly of small molecules. The self-assembly phenomenon provides fibrillar structures able to entrap the water and to make gels. It has been shown that some of them are suitable for cell culture ${ }^{10,28-34}$. Most of them are based on peptides, often inspired from collagen sequences, but other families of LMW gelators are also promising. They have a variety of chemical compositions and also different kinds of fibers. Their size can vary from nanometric to micrometric sizes with various shapes, helicity, roughness, local stiffness and cross-link topology. The self-assembly is also much easily broken compared with polymers gels. These properties may affect bioactivity, biodegradability, cytotoxicity, clearance, immunogenicity differently compared with polymers, in a way that deserves to be studied. We focused our interest in carbohydrate-based (or "sugar-based" or "saccharide-based") low molecular weight gelators. A quite large number of those gelators are now described, but their potential as scaffold for cell culture is nearly unexplored ${ }^{35-40}$. Some recent studies have shown that an injectable saccharide-nucleoside molecular hydrogel successfully supported the growth of stem cells ${ }^{41-43}$. Two other carbohydrate derived molecular gels were also used with success for cell culture ${ }^{44,45}$. Recently, a photosensitive galactose-spiropyran based hydrogel has been described for controlled hepatocytes growth ${ }^{46}$.

In this work, the aim was to explore the potential of one family of very simple galactose-based LMW gels, based on alkylgalactonamides, for the growth of neuronal cells. To our knowledge, these materials have never been described as scaffold for cell culture. Alkyl amides derived from simple sugars (alkylaldonamides) have been recognized early as molecular gelators and can be produced at the gram scale by a one-step addition of fatty amines on sugar lactones (e.g. gluconolactone, galactonolactone). They are purified by a simple recrystallization ${ }^{47,48}$. Advantageously, the synthesis does not require coupling agents that may be difficult to remove from the final product, and the very simple chemical structure containing only a sugar head, a fatty amine and an amide bond, is expected to be non-cytotoxic. Also, despite their amphiphilic structure, they are poorly surface active that is an advantage in the prospect of using them as scaffolds for cell culture. Those compounds are known to provide quite unstable gels ${ }^{49}$. They display an unusual mechanical behavior with consistency at rest but undergoing a strong synaeresis under a tiny mechanical stress, retracting in a denser gel and expelling a large quantity of water. However, instead of alkylgluconamides, gels of alkylgalactonamides have been described to be more stable ${ }^{48,50}$. The galactonamide head may also provide a higher resistance to enzyme degradation compared with a gluconamide head and may provide a gel that will last a longer time, therefore more suitable for cell culture. Gelation in water looks like an abrupt crystallization upon cooling providing an unusual network of very large and long fibers that may match well the dimensions and stiffness for supporting neural cells. We anticipated that the fibrillar network made of very large fibers separated by very large spaces may be favorable for cell settlement in 3D. It prompted us to test further the properties of this matrix for neuronal growth in 3D. In this first approach, the objective was to explore biocompatibility of the gel alone and also the impact of the hydrogel chemical and physicochemical features (alkyl chain parity, fibers structure, network topology, solubility and mechanical strength) on the cell growth. Three gels, 
differing only by a one-carbon increment on the alkyl chain have been compared (hexyl, heptyl and octyl galactonamide, respectively named Gal-C6, Gal-C7 and Gal-C8). The impact of this subtle one carbon difference on the cell growth has been highlighted using a neuronal cell line to screen rapidly the different gels. Finally, the best hydrogel for cellular growth and 3D cells penetration was used in combination with human neural stem cells (hNSCs) coming from brain patient biopsies ${ }^{51,52}$ to see if the hydrogel could also support stem cell differentiation.

\section{Results}

\section{Gel preparation and morphology:}

The aldonamide molecules (hexyl galactonamide (Gal-C6), heptyl galactonamide (Gal-C7) and octyl galactonamide (Gal-C8)) have been synthesized by a simple addition reaction between a galactonolactone and a fatty amine and purified by recrystallization (see SI-1 and Figure S1-S2-S3) 47,48 . To form the gels, the resulting solids were dissolved in water at high temperature and the gelation occurred when the solution was cooled down to room temperature. Upon cooling, the GalC7 and Gal-C8 gels formed quite abruptly, and more slowly for Gal-C6 (see DSC, SI-2, Table S1). It resulted in coarse white gels that are more or less fragile and that undergo synaeresis when mechanically solicited (Figure 1). For Gal-C7 and Gal-C8, the concentrations selected correspond to the maximal solubility at high temperature, respectively $0.45 \mathrm{wt} \%$ and $0.5 \mathrm{wt} \%$. For Gal-C6, the concentration used ( $1 \mathrm{wt} \%)$ was the lowest concentration for which the gel was found resistant enough for cell culture.
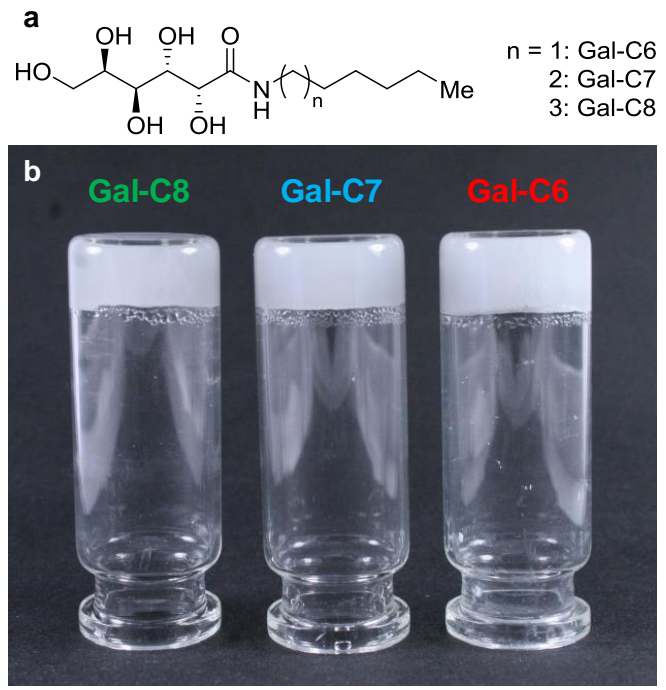

Figure 1: (a) Chemical structure of the gelators: Gal-C8: octylgalactonamide; Gal-C7: heptylgalactonamide; GalC6: hexylgalactonamide. They only differ from each other according to their carbon-chain length. (b) Gels obtained after cooling down of the hot solutions.

The macroscopic aspect of the gels was not very reproducible when prepared in small quantities directly at room temperature. When prepared in the wells of culture plates, the gels are strongly heterogeneous. They formed dense spherulitic gel aggregates dispersed in a less dense gel (see Figure 2a, "0-min"). These heterogeneous gels were not suitable gels for cell culture because they tended to disintegrate too easily. Because of the analogy of this transition with a crystallization process and since several studies have shown that the morphology of the self-assembled structures of LMWG is affected by the cooling rate ${ }^{53,54}$, the influence of the cooling rate on the gelation process was investigated. The hot solutions of the gelators, dispensed in a culture plate, underwent cooling in 
a programmable hoven from $100{ }^{\circ} \mathrm{C}$ to $25^{\circ} \mathrm{C}$ within different times: either in $15,30,60$ or 90 minutes and were compared to gels prepared from hot solutions directly dispensed in plates at room temperature and referred to as "0-min". At first sight, the gels look more homogeneous when a controlled cooling rate is applied (Figure 2a, "90 min"). The gels were then observed with optical microscopy. This technique enabled to quantify the differences between the gels, on undisturbed gels (Figure 2b). Two parameters were analyzed: the nucleation points and the apparent fiber lengths. The nucleation point density has been measured by counting the number of spherulitic aggregates per $\mathrm{mm}^{2}$. The mean values of the nucleation point density per $\mathrm{mm}^{2}$ for each gel at each cooling rate are represented on Figure $2 c$. There was a significant and strong decrease $(p<0.0005)$ of the nucleation point density when the cooling time was controlled and higher than 15 minutes for all the gels. It resulted in more homogeneous and stronger gels. The most decisive effect thus occurred as soon as a controlled cooling over 15 minutes was applied. In addition, Gal-C7 always had a lower number of nucleation points compared with the two other gels, even for the "0-min" cooling condition ( $p<0.0005)$. For Gal-C8, a 90-minute cooling decreased even more the nucleation point density compared to a 15 -minute cooling $(p<0.0005)$, that was not observed for the other gels. For this reason, a 90 minutes cooling was applied to the gels used in cell culture.

a

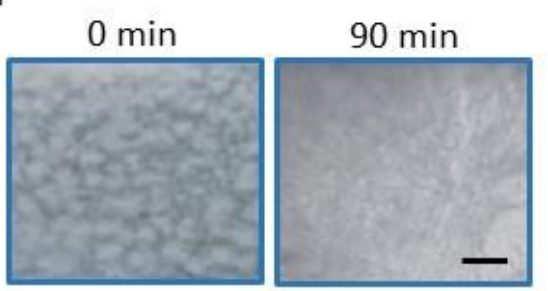

Gal-C7

b
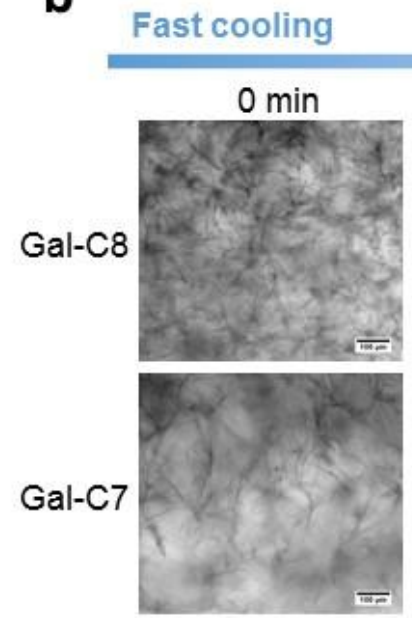

Gal-C6

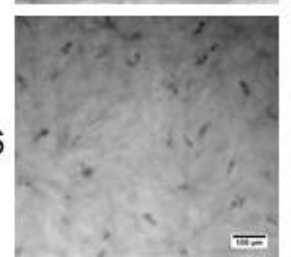

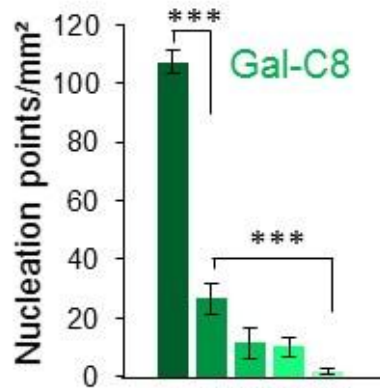

015306090
Gal-C7

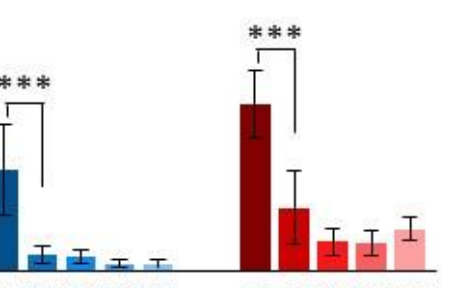

015306090

(min)
015306090

Slow cooling

C
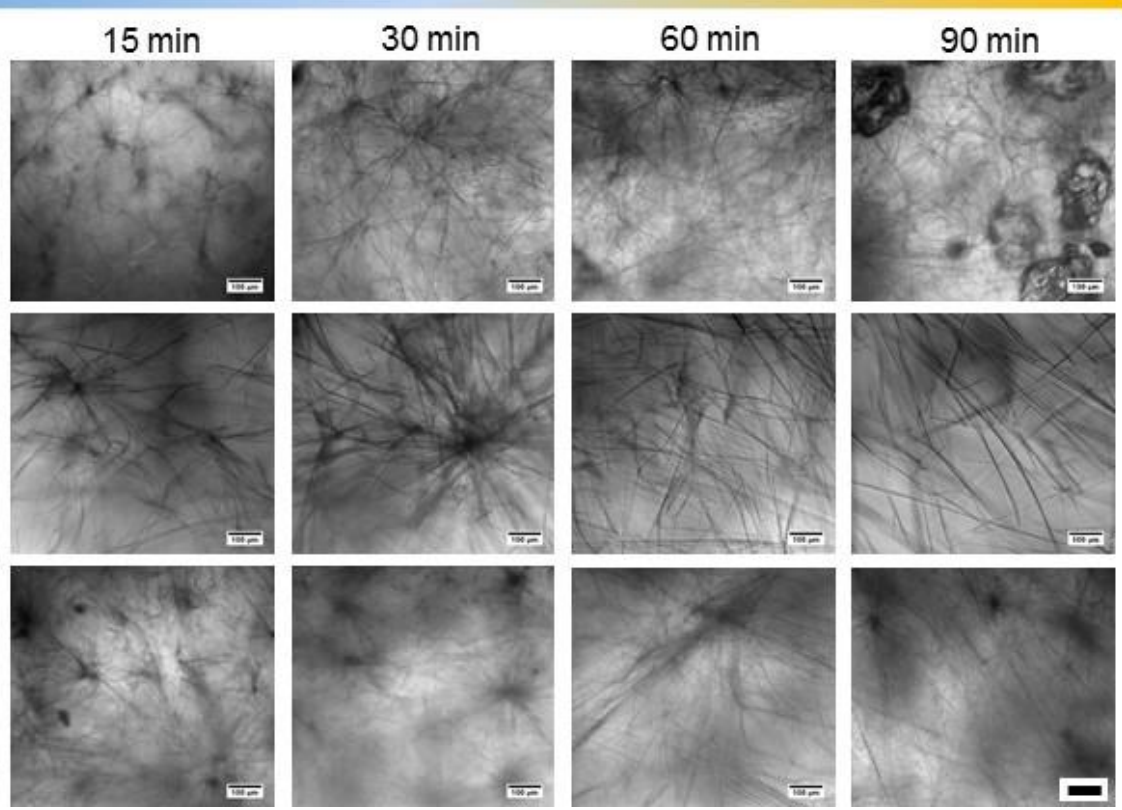

Figure 2: Influence of the controlled cooling rate on the gels aspect. a. Typical macroscopic view of Gal-C7 gels prepared with an instantaneous cooling of a hot solution of Gal-C7 ("0-min") or with a 90-min cooling (scale bar: $1 \mathrm{~mm}$, small white dots correspond to nucleation points). b. Bright-field microscopy observations of the three different gels prepared with different cooling rates, from an instantaneous cooling ("0-min") to slower cooling rates (time in min to go from $100{ }^{\circ} \mathrm{C}$ to $25^{\circ} \mathrm{C}$ ) (scale bars: $100 \mu \mathrm{m}$ ). c. The nucleation point density was 
then quantified on each microscopy image and reported as a graph. The data represents the mean +/- SD of the number of nucleation points per $\mathrm{mm}^{2}$ ( $n=6$ per gel for the different cooling rates). Asterisks represent statistical significance between 0 and 15 min cooling or 15 and 90 min for the different gels $(* * *: p<0.0005)$.

The fiber lengths were also measured for each gel and each condition (Figure 3). They correspond to apparent lengths of fibers. Only fibers exceeding the threshold of $4 \mu \mathrm{m}$ in length, below $550 \mu \mathrm{m}$ and large enough have been counted with this technique. Concurrently to the decrease of the nucleation points, a significant increase in the fiber length was observed when a 90 minutes cooling time was applied compared to the " $0-\mathrm{min}$ " condition, for all the gels ( $p<0.0005$ between the 3 gels), and most of the effect occurred between 0 and 15 minutes (Figure 3a). It means that just avoiding a sudden cooling of the hot solutions already enables the development of much longer fibers. In addition, several features are specific to Gal-C7. First, Gal-C7 has significantly longer apparent fibers than the two other gels when cooled over 90 minutes (Figures 3a and 3c). Secondly, the length distribution for Gal-C7 is more widespread than for Gal-C8 and Gal-C6. Tertiary, Gal-C8 and Gal-C6 show a much higher population of very short fibers, even with a 90-min cooling (Figure 3c), and these gels look much denser. Finally, Gal-C7 forms fibers that can reach up to $500 \mu \mathrm{m}$ and over. The combination of these factors - the nucleation point density and the fiber length - accounts for the aspect and the stability of the gels. Controlling the cooling rate during the gelation was thus a convenient method to obtain homogeneous and more stable gels in a reproducible way. 

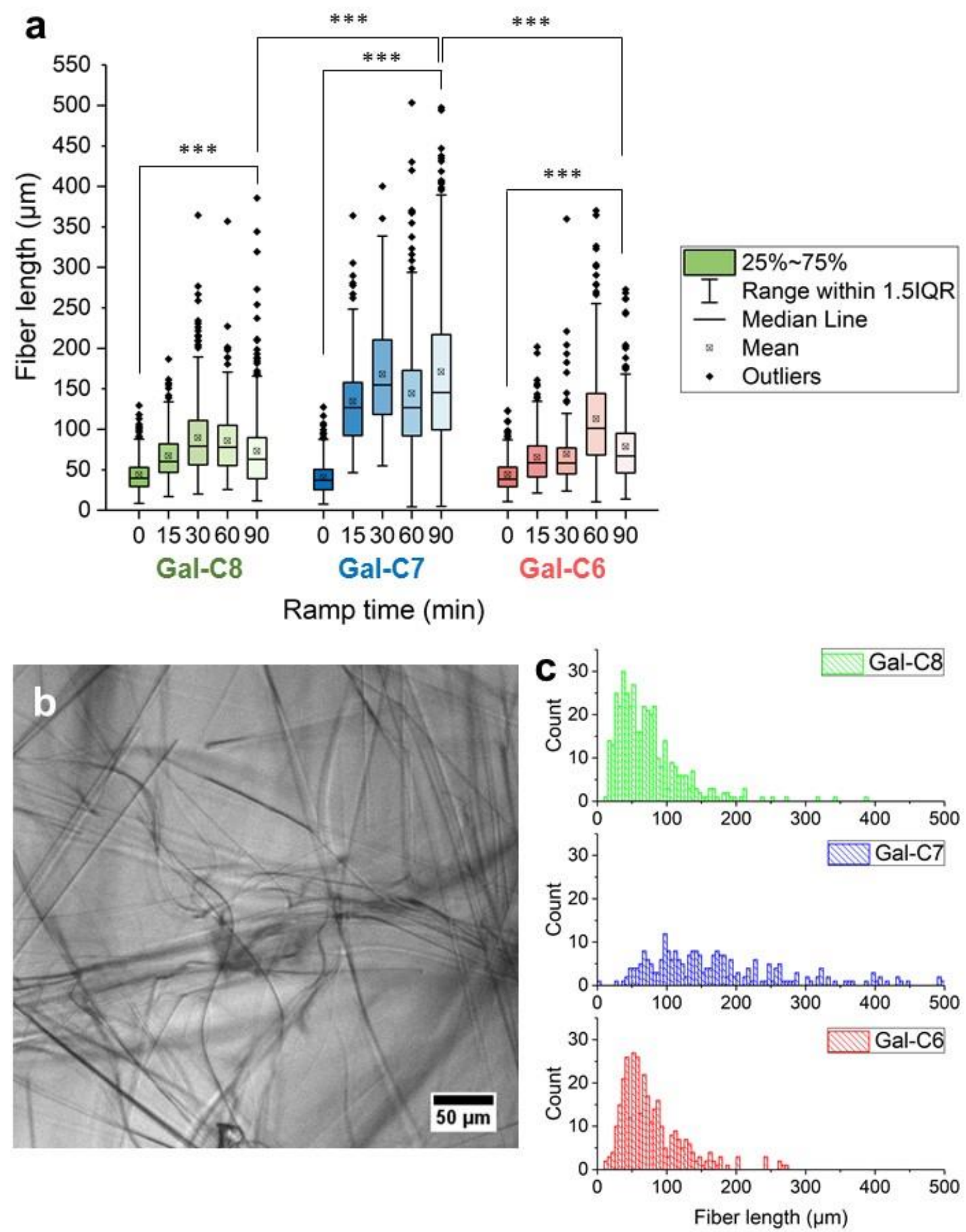

Figure 3: Fiber lengths analysis of gels prepared at different cooling rates. a. Gal-C8,C7,C6 solutions were allowed to gel at different cooling rate (time in min to go from $100^{\circ} \mathrm{C}$ to $25^{\circ} \mathrm{C}$ ), the apparent fiber lengths were then analyzed on bright-field microscopy observation using ImageJ software (NeuronJ plugin). Asterisks represent statistical significance between 0 and 90 -min cooling rate for each gel or between the 90-min cooling rates of the three gels $(* * *: p<0.0005)$. b. Typical picture of bright-field microscopy observation used to measure the apparent fiber length (here Gal-C7 with a 60-min cooling rate). c. Representative histogram of the fiber lengths obtained for the three gels for a 90-min cooling rate.

Insights in the microscopic structure of the fibers were obtained from Transmission and Scanning Electronic Microscopy images (TEM and SEM) (Figure 4). From the observation of the fibers sampled on the TEM grids, Gal-C7 and Gal-C8 showed fibers of similar width (median width for a 60-min cooling: $1.1 \mu \mathrm{m}$ and $1.3 \mu \mathrm{m}$ respectively), whereas Gal-C6 showed thinner fibers $(0.3 \mu \mathrm{m})$. The 
cooling time did not seem to have a major effect (see SI-3, Figure S4). For Gal-C7 and Gal-C8, TEM and SEM also revealed that the fibers are very large and flat ribbons. The width can reach $35 \mu \mathrm{m}$. It also highlights that Gal-C6 is very distinct from the two other gels, with much thinner ribbons with a maximal width of $12 \mu \mathrm{m}$ (see SI-3, Figure S4). This flat morphology and the large width may have an important impact on the interaction of the cells with this substrate. From the cryo-Scanning Electron Microscopy images, a coarse estimation of the thickness was obtained from few fibers conveniently oriented: $150 \pm 100 \mathrm{~nm}$ for Gal-C8 and Gal-C7 and $100 \pm 50 \mathrm{~nm}$ for Gal-C6.
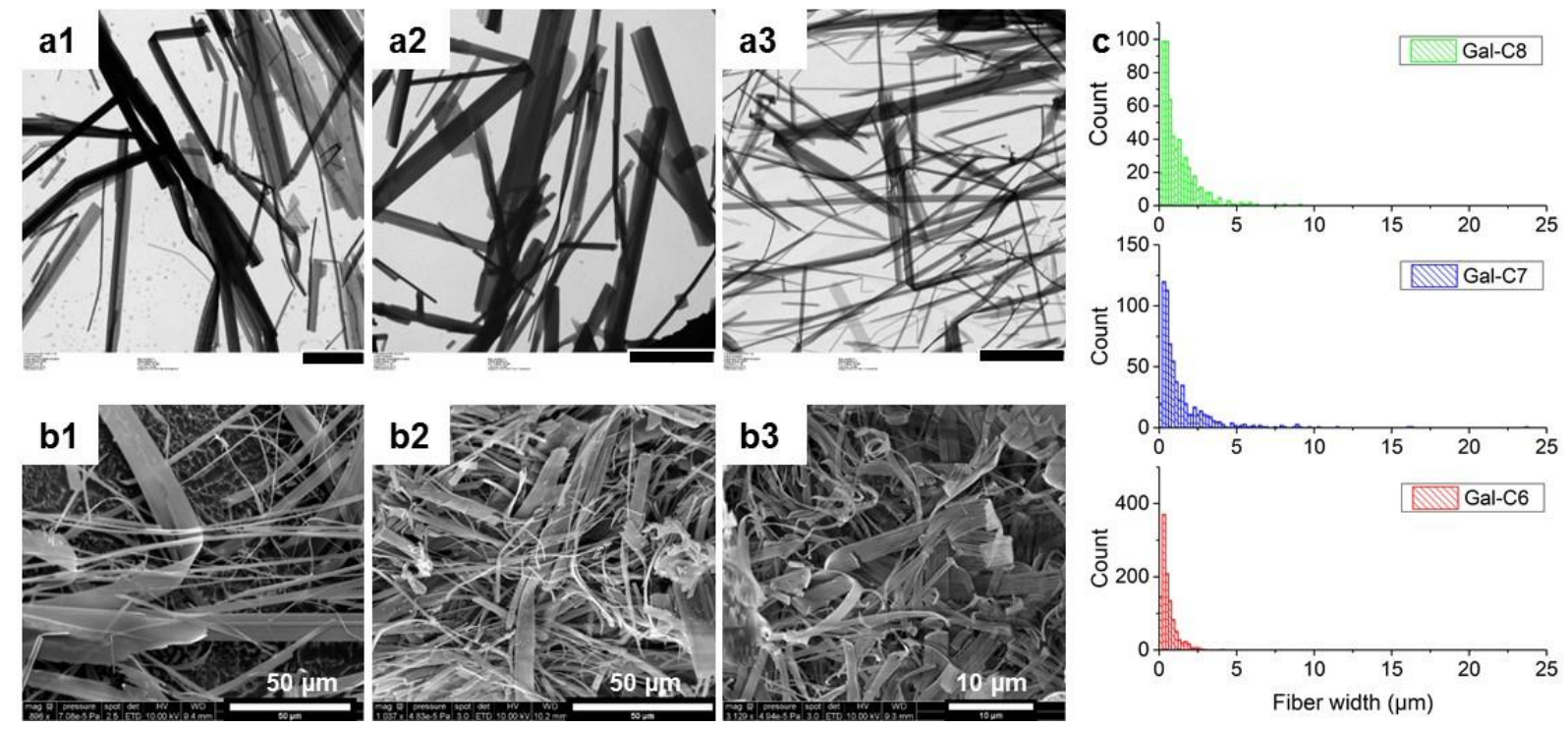

Figure 4: Microscopic structure of the gel fibers. a1-a3: TEM images of Gal-C8, Gal-C7 and Gal-C6 gels (scale bar: $10 \mu \mathrm{m}$ ) and b1-b3: cryo-SEM images of Gal-C8, Gal-C7 and Gal-C6 gels prepared with a "0-min" cooling. c. Histograms of the apparent fiber widths of the three gels for a "0-min" cooling time (measured on the TEM images).

The three gels (90-min cooled) have been also analyzed by Small Angle X-Ray Scattering (SAXS) providing an insight in the molecular packing of the gelator molecules into the fibers and a measure of the fiber thicknesses (see SI-4). Strong scattering peaks at relative position ratios 1:2:3:4. etc... evidenced a well-defined lamellar organization, with a spacing of $36.5 \AA$; $35.2 \AA$ and $32.7 \AA$ for, respectively Gal-C8, Gal-C7 and Gal-C6 (Figure S5 and Table S2) ${ }^{55}$. The decrease of the lamellar spacing from Gal-C7 to Gal-C6 is roughly the length of $2 \mathrm{C}-\mathrm{C}$ bond $(2 \times 1.5 \AA)$. Conversely, the difference between Gal-C7 and Gal-C8 is only $1.3 \AA$. Since it is too small to be attributed to the chain length difference, it means that there is a difference of molecular packing between Gal-C7 and Gal$\mathrm{C} 8$, probably related to the degree of fatty chain interdigitation or to molecular conformations. Interestingly, only in the case of $\mathrm{Gal}-\mathrm{C7}$, an additional interaction peak corresponding to an interaction distance of $38.3 \AA$ and a thickness around $170 \mathrm{~nm}$ is observed. This peak is indicative of the coexistence of a second molecular arrangement in Gal-C7, with a lower degree of organization. The fiber thicknesses can be deduced from the linewidth of the Bragg peak, given the highly ordered arrangement of the fibers ${ }^{56}$. The thicknesses measured are around $250 \pm 50 \mathrm{~nm}$ for the three gels that is consistent with the thicknesses observed by cryo-SEM. 
The mechanical properties of the gels have been first assessed by dynamic rheology. For these measurements, the gels were "0-min" cooled, because controlled cooling was not possible in the rheometer geometry that is not sealed (evaporation at high temperature would dry the gel). The rheograms (Figure 5a and SI-5, Figure S6) typically display the characteristics of a gel: both the elastic modulus (G') and the viscous modulus (G") exhibit plateaus and $G^{\prime}$ is about 10 times larger than $G^{\prime \prime}$, over the full range of frequency probed $(10$ to $0.1 \mathrm{~Hz}$ ). Moduli were quite low, from 2 to $50 \mathrm{kPa}$ (Table 1 ), showing that they are very soft gels. There is a significant difference of elastic moduli $G$ ' for the three gels, that decrease in the order: Gal-C6 (50 kPa) >> Gal-C7 (7kPa) > Gal-C8 (3kPa) (Table 1). In the case of "0-min" cooled gels, Gal-C6 appears to be a much stronger gel, ten times more rigid compared with Gal-C7 and Gal-C8.

a

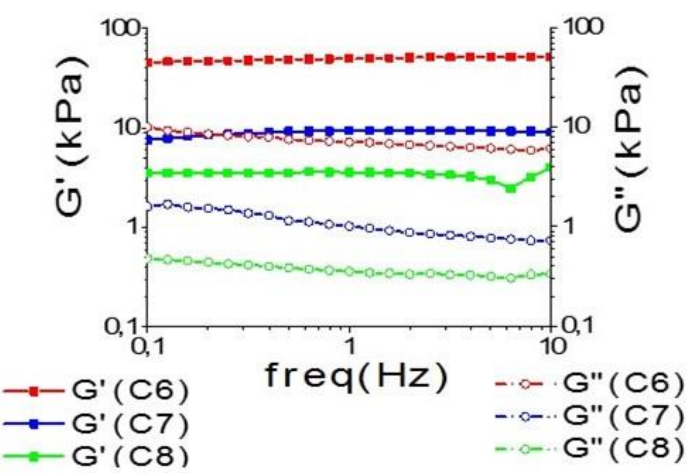

b

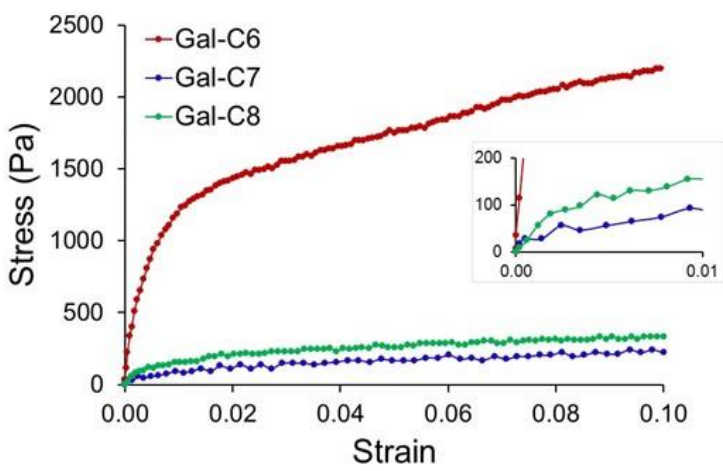

Figure 5. a. Rheology analysis of the three gels ("0-min" cooling): variation of the elastic (G') and viscous (G") modulus with the frequency $\left(\right.$ strain $=2.10^{-3}(0.2 \%), T^{\circ}=37^{\circ} \mathrm{C}$ ). b. Uniaxial compression of gels cylinders $(90-\mathrm{min}$ cooling; fast compression speed: $5 \mathrm{~mm} / \mathrm{s}, \mathrm{T}^{\circ}=20^{\circ} \mathrm{C}$, see also SI-6). Gel concentrations for both rheology and compression tests: Gal-C6: 1wt\%; Gal-C7: 0.45\%; Gal-C8: 0.5\%.

Table 1. Elastic (G') and viscous (G") moduli measured by dynamic rheology, at $1 \mathrm{~Hz}, 0.2 \%$ strain, $37^{\circ} \mathrm{C}$. Yo: Initial moduli of the gels measured by uniaxial compression tests at different compressive rates, $20^{\circ} \mathrm{C} .5 \mathrm{~mm} / \mathrm{s}$ reflects an intermediate loading rate condition, $0.1 \mathrm{~mm} / \mathrm{s}$ reflects a quasi-static loading rate condition.

\begin{tabular}{|lllll|}
\hline & $\mathrm{G}^{\prime}(1 \mathrm{~Hz})$ & $\mathrm{G}^{\prime \prime}(1 \mathrm{~Hz})$ & $\mathrm{Y}_{0}(5 \mathrm{~mm} / \mathrm{s})$ & $\begin{array}{l}\mathrm{Y}_{0} \\
\mathrm{kPa}\end{array}$ \\
& $\mathrm{kPa}$ & $\mathrm{kPa}$ & $\mathrm{kPa}$ \\
& $37^{\circ} \mathrm{C}$ & $37^{\circ} \mathrm{C}$ & $20^{\circ} \mathrm{C}$ & $20^{\circ} \mathrm{C}$ \\
\hline GalC6 & 50 & 3 & $153 \pm 31$ & $39 \pm 7$ \\
GalC7 & 7 & 1 & $14 \pm 3$ & $8 \pm 2$ \\
GalC8 & 3 & 0.5 & $24 \pm 3$ & $12 \pm 4$ \\
\hline
\end{tabular}

Since the rheological tests could not be performed on slow cooled gels but only on "0-min" cooled gels, the mechanical properties of the gels were also measured by uniaxial and unconfined compression tests. With this method, a controlled cooling of 90 minutes has been applied to the gel solutions into sealed molds. The uniaxial and unconfined compression tests were performed at low strain, from 0 to $10 \%$ strain, at two compressive rates $(5 \mathrm{~mm} / \mathrm{s}-0.1 \mathrm{~mm} / \mathrm{s}$ ) (Figure $5 \mathrm{~b}$ and $\mathrm{SI}-6$, Figures S7-S8-S9). The curves display the features of stress-strain curves of cellular solids, such as foams or sponges at low strains ${ }^{57}$. Similar curves have been also described for fibrin networks, in which different phenomena such as fibers bending, buckling, packing and water expulsion occur during compression ${ }^{58,59}$. The general trend on the Gal-C6, Gal-C7 and Gal-C8 stress-strain curves is a softening when the strain increases. Two regimes have been identified. At very low strain, the curves display a higher slope, from which the initial moduli $\left(\mathrm{Y}_{0}\right)$ have been measured. They are quite similar for Gal-C7 $(14 \pm 3 \mathrm{kPa}$ at $5 \mathrm{~mm} / \mathrm{s})$ and Gal-C8 $(24 \pm 3 \mathrm{kPa}$ at $5 \mathrm{~mm} / \mathrm{s})$ and much higher for Gal-C6 $(153 \pm 31$ $\mathrm{kPa}$ at $5 \mathrm{~mm} / \mathrm{s}$ ) (Figure $5 \mathrm{~b}$, Table 1). These results are in accordance with the macroscopic observations: during handling, Gal-C6 gels are able to sustain a higher stress or strain before 
collapsing compared with Gal-C7 and Gal-C8 gels. When the compression increases, the fibers tend to bend, buckle and pack and a fraction of water is also expulsed. These different phenomena lead to a progressive decrease of the gel resistance (softening), measured by a decrease of the modulus for all the gels. They are partly reversible upon unloading. As a result, a second regime is observed at higher strain, with a very low modulus, between $\approx 1$ to $5 \mathrm{kPa}$ for all the gels. It corresponds to the residual stiffness of a gel partly compressed.

Both rheology and compression tests show that these gels are very soft. On all measurements, GalC6 is clearly stiffer. As explained above, a higher concentration for Gal-C6 gels (1\%) had to be selected in order to get gels able to withstand cell culture conditions. At lower concentrations, the gel is broken up during biological tests. However for mechanical testing purposes, it was possible to make self-standing Gal-C6 gel cylinders at a lower concentration $(0.65 \%)$ by slow cooling. Their moduli were respectively $25 \pm 1 \mathrm{kPa}(5 \mathrm{~mm} / \mathrm{s})$ and $19 \pm 2 \mathrm{kPa}(0.1 \mathrm{~mm} / \mathrm{s})$, close to the values obtained for Gal-C7 (at $0.45 \%$ ) and Gal-C8 (at $0.5 \%$ ) at similar concentrations. This supplementary data showed that the higher stiffness observed for Gal-C6 gels at $1 \%$ would be mainly related to its higher concentration. Finally, the moduli of Gal-C7 and Gal-C8 in quasi-static loading conditions (resp. $8 \pm 2$ and $12 \pm 4 \mathrm{kPa}$ at $0.1 \mathrm{~mm}^{-\mathrm{s}^{-}}$) have the order of magnitude the closest from the brain rigidity that is between $0.5-2.5 \mathrm{kPa}$ in similar loading conditions ${ }^{27}$.

\section{Cell growth of a neuronal cell line with the aldonamide gels}

The suitability of the gels as support for cell growth has been then investigated (Figure 6). In the present study, the aim was to elucidate the key features related to the gels on their own. Gels were so prepared without any additional adhesion molecules. Moreover, cell culture conditions were settled to obtain a gel thick enough (3-4 $\mathrm{mm} /$ well) to ensure that the cells felt only the mechanical properties of the gel. Cells were seeded on the top of the gels.

First, the biocompatibility of the gels has been assessed qualitatively with a live-dead cell assay using the neuronal cell line Neuro2A (Figure 6a). It enabled to quickly eliminate conditions unsuitable for cell culture. This assay measures the intracellular esterase activity (in green) and reveals the plasma membrane integrity (in red). Those preliminary viability experiments prior to cell growth tests were performed on "0-min" cooled gels. Live cells were found on all tested gels. After 7 days of culture, Gal-C7 gels always displayed a higher cell density compared with the two other gels with $98 \pm 1 \%$ of cell viability. Some toxicity was detected with the Gal-C6 gel with dead cell aggregates sometimes observed. The percentage of viability was evaluated at $78 \pm 6 \%$ for Gal-C6 gels and at $81 \pm 13 \%$ for GalC8 gels. The cell density at the end of the experiment seemed however lower in the gels than in a 2D control without gel, even with the Gal-C7 gel. To explore this point, the cell growth with the different gels with or without a controlled cooling was quantified using a MTT assay (Figure $6 \mathrm{~d}$ and SI-7, Figure $\mathrm{S10})$. In the case of "0-min" cooled gels, collecting data was quite difficult because many gels tended to break up during experiment, unless very careful washings were made. Conversely, 90-min cooled gels which are more homogeneous and resistant did not break up (Figure 6b). For the Gal-C7 gel with a controlled cooling, cells seemed to penetrate the gels and not only to stay on the surface (Figure $6 c$ ). For this reason, two cell densities were used (35000 and 70000 cells/well) in order to avoid a low growth due to a too important cell dispersion. The MTT assays were performed after 1 day and 4 days of culture without changing medium to avoid cell loss during culture medium renewal. The cell growth with the hydrogels was then compared to a control well corresponding to a culture reaching confluence after 4 days on a 2D plastic surface.

Concerning the impact of the cooling rate, MTT assays showed that for the three gels there was not a significant difference of cell growth between gels prepared with a "0-min" cooling or a 90-min cooling (SI-7, Figure S10). The gels without controlled cooling are too fragile for a practical use in cell culture, but the morphology of the gels, that differs mainly on the fiber length and the number of 
nucleation points, did not really affected the cell growth. Concerning the difference between the three gels, in all MTT experiments, the cell growth between day 1 (D1) and day 4 (D4) has been found significantly higher for Gal-C7 compared with Gal-C8 and Gal-C6, as showed by the analysis of variance ( $p<0.05$ according to ANOVA statistical analysis) (Figure 6d). For Gal-C6 and Gal-C8 gels, the cell number was not statistically different between D1 and D4. Cells seemed to stay more in a "latency stage". A non-controlled variability in growth results was observed with the Gal-C8 certainly due to its high gelation point, which made it hard to manipulate. With the Gal-C7 gel, when the cell density seeded was sufficient (70 000 cells/well instead of 35000), the cell number increases more than 2.9 fold during the culture period $(p<0.05)$. The growth was however slower than on a $2 \mathrm{D}$ control where a 4 fold increase was observed between D1 and D4 $(p<0.0005)$. The cell density needed on this kind of support was higher, certainly due to the cell penetration within the fibers network. This phenomenon has already been pointed out in other studies. Different cell lines have already shown reduced proliferation rate in 3D cultures compared to those cultured in 2D but the behavior of cells grown in 3D seems to better reflect in vivo cellular response ${ }^{3,8}$. Overall, these results emphasize that the Gal-C7 gel is suitable for cell growth, while Gal-C6 and Gal-C8 are less favorable. The three gels only differ by a one-carbon increment in their alkyl chain, but this tiny difference affects many physicochemical properties of the gels (microscopic and network topography, mechanics, solubility, gelator release...) that probably affects also their biochemical properties (metabolic pathways...) and their interactions with the cells. 
Gal-C8
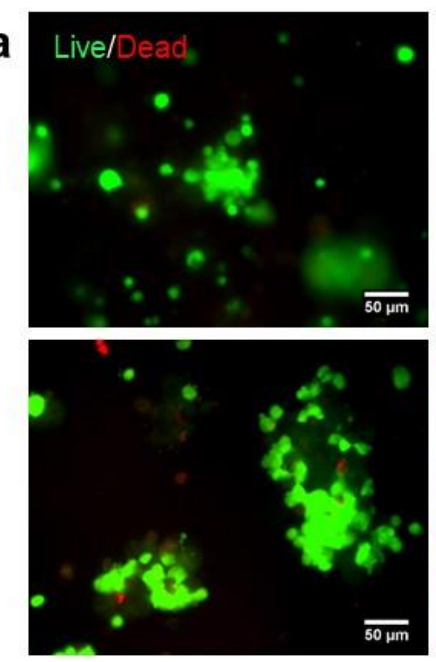

Gal-C6
Gal-C7
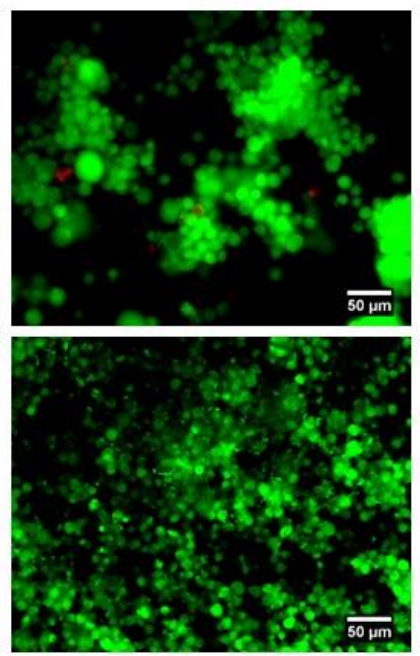

$2 \mathrm{D}$ control
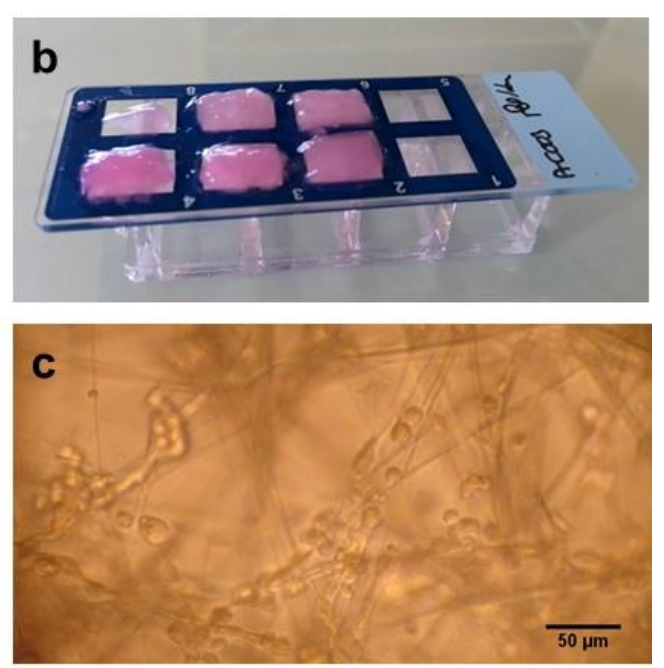

$\overline{50 \mu \mathrm{m}}$

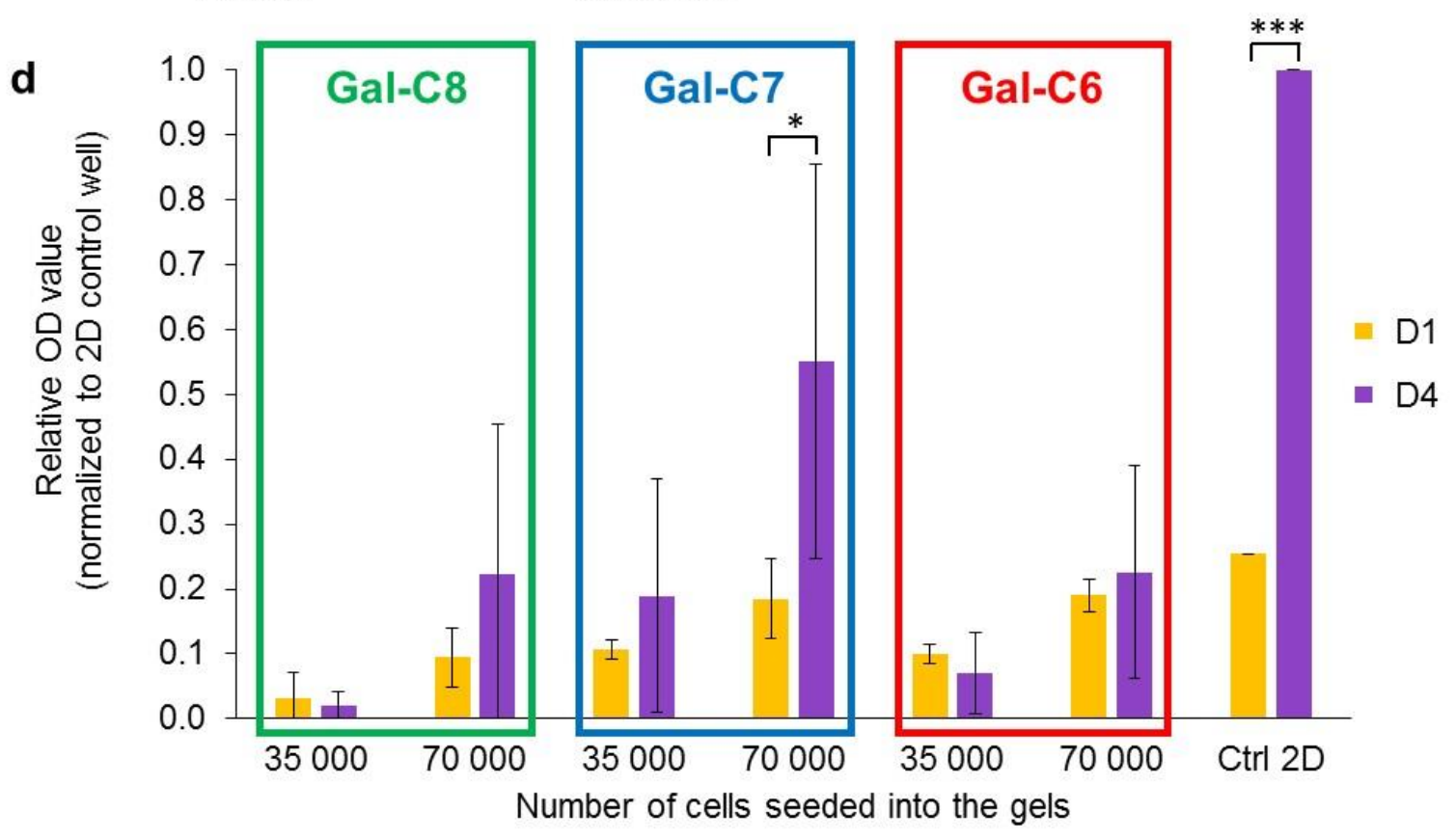

Figure 6: Cell culture assays and growth quantification with the aldonamide gels. a. Live/Dead staining of Neuro2A cells on the galactonamide gels after 7 days of culture ("0-min" cooled gels, scale bar: $50 \mu \mathrm{m}$ ). b. Typical aspect of 90-min cooled Gal-C7 hydrogels after 7 days of cell culture on an 8-well chamber slide (after chamber removal). The two wells at the right are controls. c. Neuro2A cells were observed directly into the gel fibers by bright-field microscopy (Gal-C7 90-min cooled gel). $\mathrm{d}$. MTT test after 1 and 4 days of cell culture with Neuro2A cells on the different gels prepared with controlled cooling rate. The results represent the blankcorrected mean OD value +/- SD ( $n=3)$. Asterisks indicate statistical significance $(*: p<0.05$ and $* * *: p<$ 0.0005).

\section{D cell penetration and Primary hNSCs growth on Gal-C7 gel}

The observations by conventional optical fluorescence microscopy (Figure 6b) already highlighted a probable 3D penetration of the cells into the gels and not only a "pseudo-3D" growth at the surface of the gels. Such penetration was not observed with Gal-C7 hydrogels prepared without controlled cooling. To confirm these previous observations a confocal study was performed with the $90-\mathrm{min}$ cooled Gal-C7 hydrogel, with the cells still seeded only on the top of the hydrogels. To preserve the 
scaffold structure and to easily visualize the cells without extensive gel manipulations, a Neuro2A cell line expressing the GFP protein was generated. First the gels were observed by laser reflection technique without any staining. Only the large fibers can be observed by this technic (Figure 7a-c and SI-8, Figures S11-S12). Cells with a quite round shape were observed throughout the scaffold and showed the capacity to penetrate approximately up to $200 \mu \mathrm{m}$ into the scaffold. Samples were also incubated with FITC-labeled polylysine. It enabled to observe also the narrow gel fibers with fluorescent confocal microscopy (Figure 7d). The coupling of the two techniques highlighted quite well the complex architecture of the scaffold and the interaction with the cells. It showed how the wide and straight fibers were linked together by a network of narrower and flexible fibers, not visible by reflection. The cells were nested into this scaffold often in small clusters, interacting with each other and with several large or narrow fibers. These images confirm that the 90-min cooled Gal-C7 gel is suitable for neuronal cell growth, including growth in 3D.
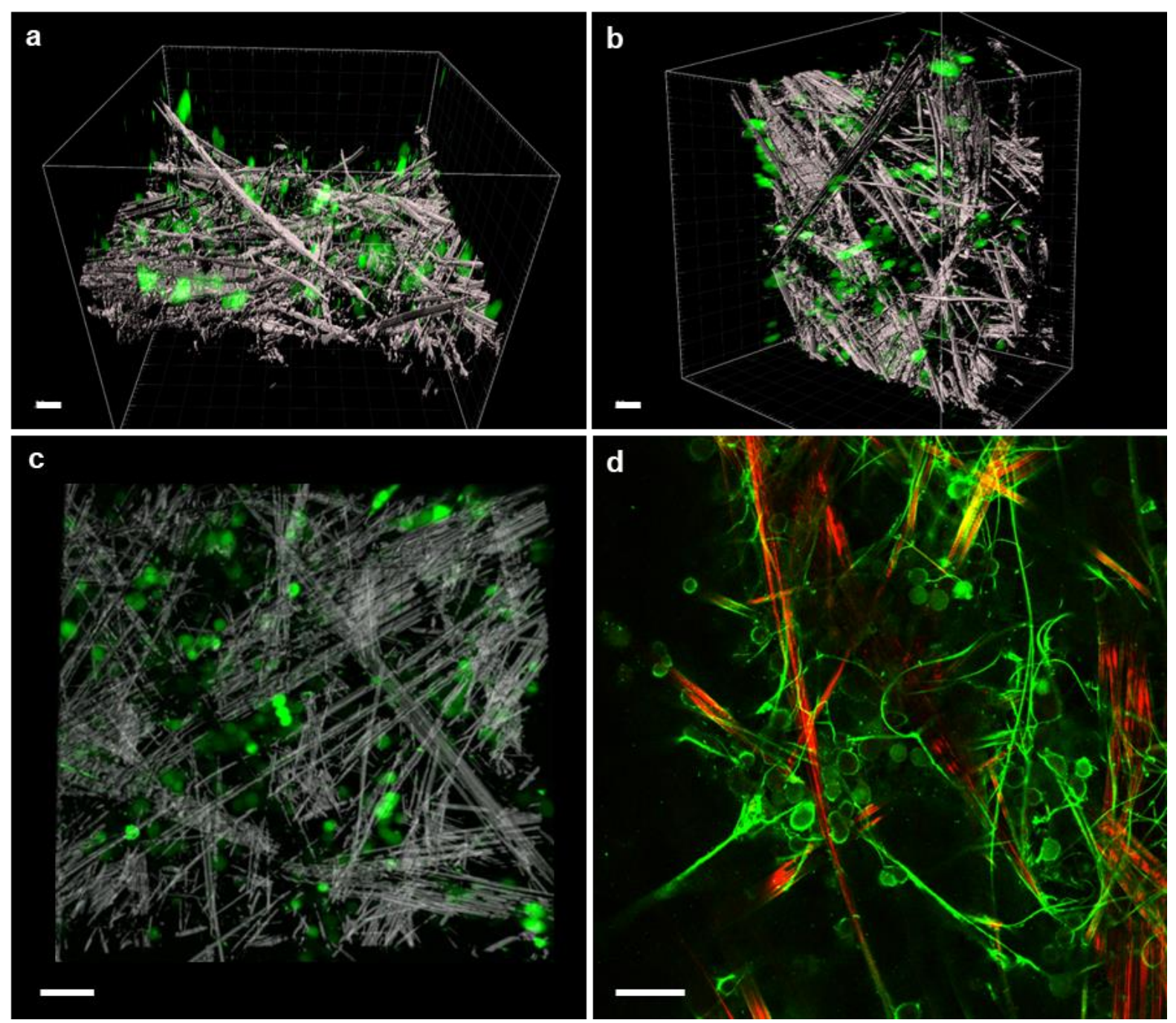

Figure 7: 3D penetration of GFP-Neuro2A cells into a Gal-C7 gel (90-min cooling) after 5 days. Confocal microscopy observations of the gel by laser reflection technique and by fluorescence (see also details of the $z-$ stacks in SI-8, Figures S11-S12). (a,b,c): fibers in white (reflection), cells in green (fluorescence). (a,b): perspective views and (c) enlargement. (d): image after incubation of the gel with FITC-polylysine. Wide fibers in red (reflection), narrow fibers and cells in green (fluorescence). scale bar: $50 \mu \mathrm{m}$.

Finally, a study was performed with human neural stem cells from brain patient biopsies, seeded on a 90-min cooled Gal-C7 gel (Figure 8). After 7 days of culture, reflection microscopy (Figure 8a) or 
live/dead cell assay (Figure 8b) showed live stem cells throughout the gel. As for the Neuro2a cells, the hNSCs were most of the time present as small clusters or neurospheres-like structures into the hydrogels showing also a clear interaction between cells and between cells and gel fibers. These techniques did not allow to really visualize neurofilaments. Nevertheless, they showed that the loose fiber meshing allowed a real self-assembling and self-organisation of the cells in 3D structure between the fibers.

To visualize the differentiation potential of the hNSC in the Gal-C7 scaffold and neuronal network formation, hNSC were seeded at high density and immunostaining was performed after 7 days of culture (Figure $8 \mathrm{c}$ and $8 \mathrm{~d}$ ). An embedding procedure adapted from "CLARITY" was used ${ }^{60}$. It enabled to embed the gels in polyacrylamide to preserve the fragile cellular network. The gel fibers were dissolved during the procedure, revealing only the cell network.

As previously described for hNSC, differentiation into glial cells was observed as assessed by immunostaining for the glial fibrillary acidic protein (GFAP) (Figure 8c). Likewise, numerous positive cells for the early neuronal marker tuj-1 were observed (Figure 8d). For both markers, a robust network was observed with an important neurite outgrowth. Interestingly, the morphologies of the two networks seem rather different. Glial cells formed a diffuse network, contrasting with straight neurites projected by the neuronal cells. The latter are often organized in bundles that seem to have followed the wide and straight gel fibers. Apart from these bundles, curved neurites were also observed, both highlighting the 3D permissive nature of the hydrogel. These data clearly indicate that the Gal-C7 hydrogel can support adult hNSC differentiation and cell-cell interaction in 3D environment even if long term experiments are still needed to study expression of more mature neuronal markers. 

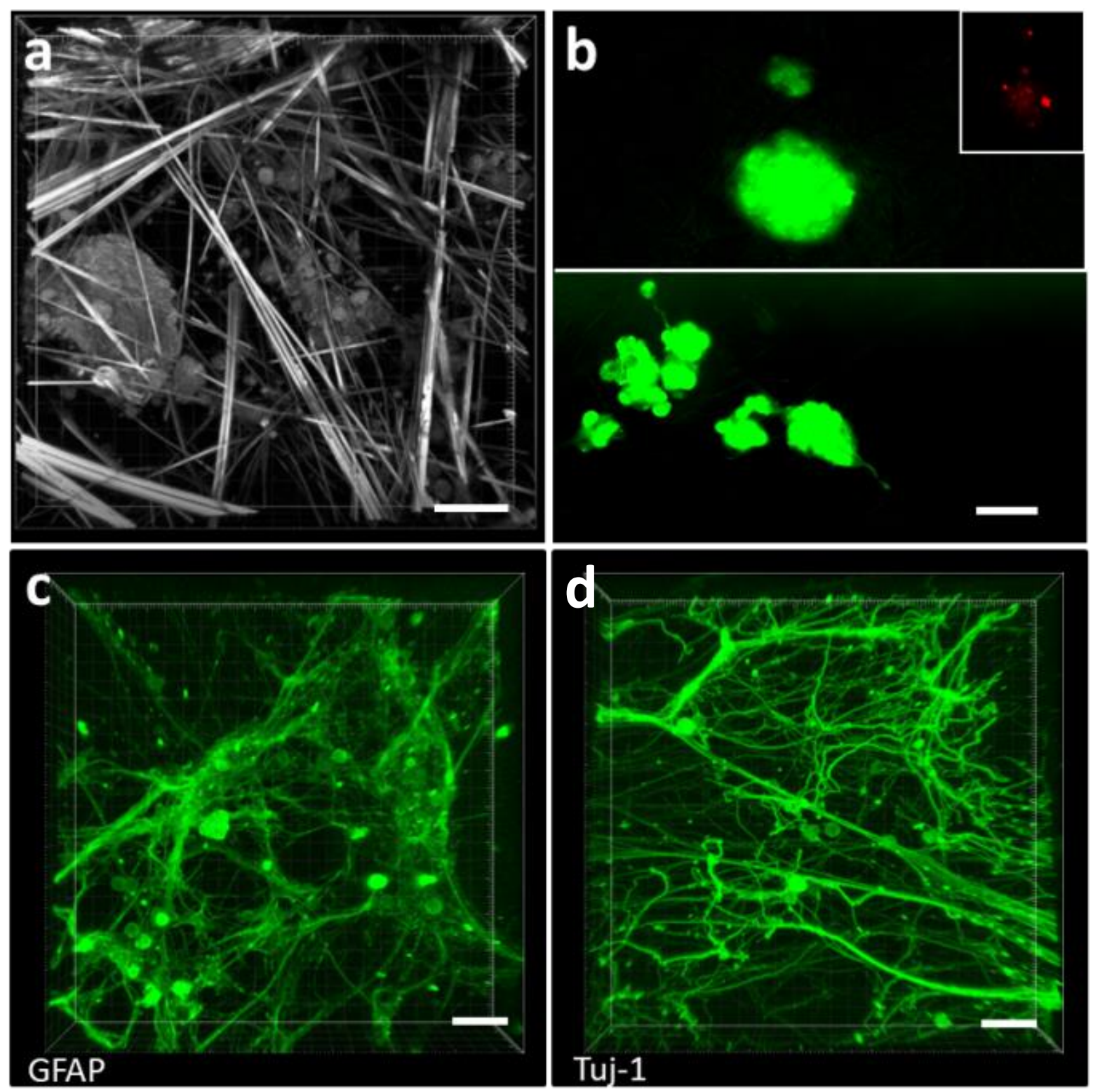

Figure 8: Human neural stem cell differentiation on Gal-C7 aldonamide gel. Human adult neural stem cells extracted from patient brain biopsy after 7 days of culture on the Gal-C7 gel in differentiation conditions. (a) Laser reflection microscopy observation of hNSC in the gel fibers and (b) live/dead cell staining assay. The insert represents the red channel alone where only few dead cells were observed, as usual, in the core of the neurospheres. Immunostaining was performed to observe the cellular neural network with GFAP (Glial fibrillary acidic protein), marker of glial cells (c) and Tuj-1 ( $\beta 3$-tubulin), marker of neuronal cells (d) (scale bar: $50 \mu \mathrm{m})$. 


\section{Discussion}

New supramolecular hydrogels suited for neural cell culture have been found in this study. The alkylgalactonamide hydrogels display fibers with original dimensions, structures and entanglements. They form long ribbon-like fibers that can reach several hundreds of micrometers in length and several micrometers in width. The meshing also is quite loose. Nevertheless, the three gels do not have exactly the same properties. They affected to some extent the cell growth. The different features we have studied that differentiate the three gels are the following: chain parity; fiber dimensions and distribution; solubility; macroscopic stiffness. Those factors are not independent, because the chemical structure of the gelator itself affects the physicochemical properties of the gel. Nevertheless, it is worth gathering and comparing here the results of the cell growth on the three gels in relation with the gel physicochemical properties investigated.

The results tend to show that the 90-min cooled Gal-C7 gel is the most suitable scaffold for cell culture, according to both dead-live, MTT assays and practical issues. This gel has the longest and widest straight fibers and the smallest population of small fibers. Its macroscopic stiffness is very low, around $15 \mathrm{kPa}$ (at high compression speed), its solubility is also low $(1.2 \mu \mathrm{mol} / \mathrm{mL}$, see SI-10, Table 3) and it is the only one of the series with an odd number of carbons in the alkyl chain. It is also more practical to handle compared with Gal-C8. In addition, the slow cooling process brought to this gel an advantage mostly in terms of gel self-standing, handling, homogeneity, 3D penetration and neurite guidance.

Gal-C6 seems the least favorable even if some cells can stay alive during 7 days of culture. Most cells cultures stagnate between day 1 (D1) and day 4 (D4) and several clusters of dead cells are found in dead-live experiments at day 7 (D7). It might be related to several gel features. Gal-C6 gel is the stiffer ( $153 \pm 31 \mathrm{kPa}$ at high compression speed). Gal-C6 also has a five-fold higher solubility compared with the other two gelators $(5.0 \mu \mathrm{mol} / \mathrm{mL}$, see SI-10, Table 3) and it had to be used in higher concentration. Since cytotoxic effects are concentration dependent, those factors have to be taken into account in future prospects on these gels, especially in the case of Gal-C6. The toxicity of shorter alkylamines is also known to be higher than the one of longer alkylamines ${ }^{61}$. Otherwise, this molecule gives gels with much shorter and thinner fibers. In the case of Gal-C6, there are thus many factors that might explain the difference of cell growth compared to Gal-C7 and Gal-C8.

For Gal-C8 gels, again the cell growth appeared less favored compared with Gal-C7. The physicochemical differences between Gal-C8 and Gal-C7 gels appear a lot more subtle. Gal-C8 is less soluble than Gal-C7 (0.7 $\mu \mathrm{mol} / \mathrm{mL}$, see SI-10, Table 3). Like Gal-C7, it also has a population of long, wide and straight fibers. The mechanical properties, measured by rheology on "0-min" cooled gels and by uniaxial compression on 90 -min cooled gels are quite close for both gels. Slow cooled Gal-C8 gels are only slightly stiffer ( $24 \pm 3 \mathrm{kPa}$ at high compression speed) than Gal-C7 gels ( $14 \pm 3 \mathrm{kPa})$. Gal-C8 is harder to manipulate because of its high gelation point. The two main differences in our observations are rather: the chain parity and the difference of the fibers length distribution. Actually, an important difference can be seen on the fiber length histogram in 90 min cooled gels (Figure 3c): an important population of short fibers is observed for Gal-C8 compared with Gal-C7. This distribution corresponds to a higher density of fibers. It has been shown that nanofibers of poorly soluble self-assembling dipeptides ${ }^{62}$ or peptides ${ }^{63}$ can be detrimental for cells when penetrating through the cell membrane and tend to provoke the apoptosis of the cell. In the case of Gal-C6-C7-C8 gels, changing the cooling rate from "0-min" to "90-min" changed the fiber lengths profile (Figure 3) and the nucleation points (Figure 2) for a given gelator but it did not change strongly the cell growth in MTT experiments: the same difference of cell growth between Gal-C6, Gal-C7 and Gal-C8 is observed on "0-min" cooled gels and on 90-min cooled gels (see Figure 3a and SI-7, Figure S10). It tends to show that at least the micrometric fiber distribution might not be the most critical 
parameter explaining the difference of cell viability and growth between Gal-C6, Gal-C7 and Gal-C8. Thus other factors not addressed here should be considered further and among others the metabolic fate of the gelators.

About chain parity, it is known that the metabolic paths of odd and even chains are different ${ }^{64}$. The packing of LMW gelators is also known to be sensitive to the chain length, even for a one-carbon odd-even increment (see SAXS section and ${ }^{65}$ ). This difference then affects in cascade all the other properties of the gels from the way it self-assembles up to the effect on cell growth. For example, a previous work has shown that some gel fibers have different biological properties and cell growth according to the chirality of helixes ${ }^{66}$. We tried to obtain gels from the related odd-numbered alkylgalactonamides, Gal-C9 and Gal-C5 (see SI-9). But Gal-C9 formed very large ribbons and sheets, even much larger compared with Gal-C7 and Gal-C8 (Figure S13). It was too hydrophobic and because of that, it did not form a macroscopic gel, but only provided floating heterogeneous concentrated gelled fragments. As for Gal-C5, it formed very thin fibers (Figure S14), similar to Gal-C6 but was too soluble and its gel-sol transition was around $40^{\circ} \mathrm{C}$, too close from $37^{\circ} \mathrm{C}$. For these reasons, it was not possible to work with these related odd-numbered alkylgalactonamides.

Finally, Gal-C7 is an optimal gel within this family. It is well adapted to the growth and differentiation of neuronal cells in 3D, including human adult neural stem cells. The network organization really seems to mimic the extracellular matrix architecture. It mixes a population of very large, straight and stiff ribbons linked by a population of narrower flexible ribbons. It is also quite easy to prepare. Previous studies have shown that stem cells differentiate in neural cells when the matrices rigidity is low. More precisely, a rigidity in the range of 1-20 kPa tends to favor the differentiation in glial cells while a lower rigidity $0.1-10 \mathrm{kPa}$ tends to increase the differentiation in neurons ${ }^{22,24-26}$. Thus Gal-C7 is in the convenient range of stiffness $(Y=14 \pm 3 \mathrm{kPa}$ at $5 \mathrm{~mm} / \mathrm{s} ; \mathrm{Y}=8 \pm 2 \mathrm{kPa}$ at $0.1 \mathrm{~mm} / \mathrm{s}$, Table 1$)$ for both neuronal and glial cell growth. Actually, the results of the cell culture with hNSC demonstrate that the gel favors the differentiation into both glial cells and neurons, providing a dense interpenetrated network of neuronal cells. It is worth pointing out that the measurement of the macroscopic rigidity, as provided by rheology and compression tests, only gives the "macroscopic" mechanical properties. In fact, the cells experience a local rigidity at microscopic scale that may be different to the rigidity measured by macroscopic measurements. The presence of different kinds of fibers, some being large, straight and stiff and others being narrow and flexible may favor the dual differentiation which is required for neural tissue regeneration. It led to the growth of neurites with different morphologies, like in the brain. The dual network of fibers may help the neurites outgrowth and both the long and short distance interconnection between cells. It has also been shown also that the topography and the roughness of the fibers, at the nanometric scale can affect the cell responses ${ }^{67}$. Actually, the immunostaining revealed bundles of neurites that have followed the straight fibers (Figure 8d), probably because they follow their grooved topography. It is well observed on the widest ones (Figure $4 \mathrm{~b}$ and 7 ). This phenomenon has already been highlighted in our previous studies ${ }^{68}$. Finally, this combination of microscopic vs macroscopic properties makes these matrices very original in respect to many polymer scaffolds and other fibrillar supramolecular networks. Notably, the extension of such very flat and large fibers over several micrometers instead of twisted fibers and linked with thinner fibers is quite unique ${ }^{30}$.

The other kinds of molecular gelators already used for cell culture and based on aminoacids or saccharides, provide smaller fibers often twisted and it has been shown that this topology at the microscale has an impact on the cell adhesion and growth ${ }^{66}$. The simplicity of the chemical structure of the alkylgalactonamide gels may also be an advantage: more complex chemical functionalities may induce toxicity ${ }^{38}$. In addition, compared with peptide-based gelators, the fiber structure of allkylgalactonamides and also the molecules released are very different and will lead to differences in metabolizing. 
Still to compare with other matrices already described for neuronal cell culture, in 90-min cooled GalC7 alkylgalactonamide gels, the cells penetrated in depth in the matrix, interacted with several fibers and with other cells, forming neurosphere-like structures. They formed a dense network of cells after 7 days and less commonly, they developed straight neurite outgrowths over long distances by following the gel fibers. Its extreme softness and its highly porous network allow the migration of the neural cells throughout the network, while providing a large carrier for the cells. With regular scaffolds made of collagen I only or hyaluronic acid the neurite outgrowth is generally nor very extended neither dense ${ }^{6,10,11}$. With composite scaffolds using a combination of ECM components with silk protein ${ }^{11}$ or synthetic peptides ${ }^{11,15-17}$, much denser neurons networks are observed. However, these kinds of scaffolds are more difficult to produce. In comparison, the Gal-C7 gel also provides, but with a very simple molecule, a suitable environment for 3D growth and neural network development.

\section{Conclusion}

We showed that a very simple alkylgalactonamide molecule, the heptylgalactonamide (Gal-C7), easily prepared at the gram-scale, provided gels suitable for the 3D-culture of neuronal cells. A neuronal cell line, but also adult human neural stem cells have been grown on these gels. The gels have been made stable by a controlled cooling of the hot solutions of gelators. The controlled cooling enables the development of very large and long flat ribbons, linked by narrower ribbons, forming an adequate substrate for sustaining the cells. The entanglement of the ribbons is loose, providing large and open interspaces, not cross-linked, into which the cells can migrate and grow in 3D. This hydrogel is highly hydrated, with an aqueous phase ratio over $99.5 \%$. On the three gels studied (hexyl, hepty, octyl-galactonamide), the cells stay alive after seven days but the seven-carbon chain length galactonamide ( $\mathrm{Gal}-\mathrm{C} 7$ ) gels appeared to be the most suitable for the growth of the neuronal cells. Quite strikingly, a one-carbon increment in the alkyl chain length of the gelator affected significantly the biocompatibility. In fact, this tiny chain length difference induced a cascade of differences. It started from the self-assembly in different sizes and the morphologies of ribbons and finally affected the network organization, the stiffness and the solubility. In the case of heptyl and octyl galactonamides (Gal-C7 and Gal-C8), the stiffness lies within a suitable range for neuronal cells differentiation and growth. As a result, experiments with human adult neural stem cells (hNSC) from patient biopsies demonstrated that the scaffold is suitable for the differentiation into both glial cells and neuronal cells. It allowed the outgrowth of numerous neurites and the development of a full interpenetrated neuronal network, showing the potential of this hydrogel to support neural tissue regeneration.

\section{Experimental Section}

\section{Gelator synthesis and purification}

The galactonamides have been prepared in good yield $(\approx 70-80 \%)$ from galactonolactone and hexylamine, heptylamine and octylamine, as described in the literature ${ }^{47,48}$. They have been purified twice by recrystallization in methanol. Details of the syntheses and analysis are provided in SI-1. 


\section{Gel preparation}

Controlled cooling rate gels: a suspension of the Gal-Cn powder in pure water was prepared in a sealed vial (1 wt\% for Gal-C6; 0.45 wt\% for Gal-C7 and 0,5 wt\% for Gal-C8. Caution! Take a $10 \mathrm{~mL}$ vial for a maximum of $2 \mathrm{~mL}$ solution). It was heated at resp. $100^{\circ} \mathrm{C}, 110^{\circ} \mathrm{C}$ or $120^{\circ} \mathrm{C}$ using heating blocks, until complete dissolution. The resulting hot solution was dispensed in the wells of a cell culture plate heated at $100{ }^{\circ} \mathrm{C}: 400 \mu \mathrm{L} /$ well for 48 -well plates $\left(0.95 \mathrm{~cm}^{2}\right)$ or $300 \mu \mathrm{L}$ for a 8 -well chamber slide $(0.70$ $\mathrm{cm}^{2}$ ), providing a gel of $\approx 3 \mathrm{~mm}$ height (caution! Pressure must be released with a needle before opening the sealed hot vials). The wells were sealed with a sealing foil to avoid evaporation. The culture plate was introduced in a programmable oven (Vötsch VT 4004). The temperature of the sample was set following a three step workflow: $5 \mathrm{~min}$ at $100^{\circ} \mathrm{C}$, a temperature linear ramp from 100 ${ }^{\circ} \mathrm{C}$ to $25{ }^{\circ} \mathrm{C}$ in either $15,30,60$ or $90 \mathrm{~min}$ and finally $10 \mathrm{~min}$ at $25^{\circ} \mathrm{C}$. For culture chamber slides, a clamp was used to ensure a good sealing of the chambers.

For gels prepared without controlled cooling ("0-min" cooled gels): the gel solution was prepared as described above, and the hot solution was dispensed directly in the wells of a culture plate at room temperature and allowed to stand for 1 hour before characterization.

Differential Scanning Calorimetry (DSC) has been performed on the "0 min"-cooled gels, in a Mettler Toledo HSS8 calorimeter. The hot solution of gelator $(\approx 80 \mathrm{mg})$ is introduced in a sealed stainless steel pan and allowed to cool at room temperature. Three cycles from $10^{\circ} \mathrm{C}$ to $120^{\circ} \mathrm{C}$ at $10^{\circ} \mathrm{C} / \mathrm{min}$ or $3^{\circ} \mathrm{C} / \mathrm{min}$ under nitrogen were recorded. The transitions temperatures are reported in Table SI-2.

\section{Morphological characterization of the gels:}

Optical transmission microscopy (OM): the gels prepared in the 48-well plates, in triplicate for each cooling condition, were observed directly by optical microscopy (inverted, bright field, x10), at the end of the cooling program on undisturbed gels. Two pictures were taken per well and per gel at two places remote from each other. It resulted in 6 pictures per gel and per rate.

The nucleation points were counted manually using ImageJ counter on each photo. The mean of the nucleation sites per $\mathrm{mm}^{2}$ was calculated for the 6 pictures and reported as a function of the cooling time.

The fiber lengths analysis was done on the same six pictures over a fixed area of $0.166 \mathrm{~mm}^{2}$. The total number of counted fibers is different for each gel since it depends on the gelation, but was around 25-90 fibers on each field. All the fiber segments visible on the images were traced semi-manually using the ImageJ plugin NeuronJ and their lengths were measured. It provided the apparent lengths of fibers exceeding the threshold of $4 \mu \mathrm{m}$ in length, and below $550 \mu \mathrm{m}$ ( $\max$ of the observation field) and large enough to be visible. The results are represented as a box chart, giving the full extent of the fibers measured.

Transmission Electronic Microscopy (TEM): In two different wells prepared with or without a controlled cooling, a grid (carbon film on copper, $200 \mathrm{mesh}$ ) is inserted within the gel for 10 minutes and removed. This sampling may have taken off mainly the unbound and broken fibers of the gels and for this reason, may not be completely representative of the whole gel. The grids are observed without any staining using a Hitachi HT7700 transmission electron microscope (TEM) operating at $80 \mathrm{kV}$. The widths of all the visible fibers on the images were measured manually using ImageJ. The total number of counted fibers was also different for each gel and was counted up to 450-1700 fibers per gel. The results are represented as a box chart in SI-3.

Scanning electron microscopy (Cryo-SEM): One drop of gel was deposited on the cryo-SEM cane and frozen at $-220^{\circ} \mathrm{C}$ in liquid nitrogen. The frozen sample was fractured at $-145^{\circ} \mathrm{C}$ under vacuum in the cryo-transfer system chamber (Quorum PP3000T). The sublimation was performed at $-95^{\circ} \mathrm{C}$ for 30 min. The sample was metalized with Pd for 60s and introduced in the microscope chamber. The temperature was kept at $-145^{\circ} \mathrm{C}$. Images were recorded with a FEG FEI Quanta 250 microscope, at $5 \mathrm{kV}$ for the acceleration voltage. Some of them with a suitable orientation (around 10 to 20 measures/gel) provided a rough estimation of the fibers thickness. The statistical analysis on these 
few measures provided: Gal-C8: $136 \pm 81 \mathrm{~nm}$; Gal-C7: $157 \pm 97 \mathrm{~nm}$; Gal-C6: $105 \pm 43 \mathrm{~nm}$, giving the following ranges of thickness: Gal-C8 and Gal-C7: $150 \pm 100 \mathrm{~nm}$ and Gal-C6: $100 \pm 50 \mathrm{~nm}$.

Small Angle X-ray Scattering (SAXS): Scattering measurements have been performed on $1 \mathrm{wt} \%$ GalC6; 0.45 wt\% Gal-C7 and 0.5 wt\% Gal-C8 90-min cooled gels with a XEUSS 2.0 SAXS/WAXS laboratory beamline equipped with a $\mathrm{Cu}$ source $(\mathrm{E}=8 \mathrm{keV})$ and a pixel detector PILATUS3 $1 \mathrm{M}$ from Detrics. Two sample-to- detector distances have been used: $0.387 \mathrm{~m}$ (beam size $0.8 \mathrm{~mm}^{*} 0.8 \mathrm{~mm}$ ) and $2.5 \mathrm{~m}$ (beam size $0.5 \mathrm{~mm} * 0.5 \mathrm{~mm}$ ) allowing a q range between $0.0037 \AA^{-1}$ and $1.5 \AA^{-1}$. Samples have been mounted on a sample holder for gels. Measurements have been carried at $25^{\circ} \mathrm{C}$.

Rheology. Rheograms were recorded with a rheometer AR1000 (TA Instruments), equipped with rough plates ( $2 \mathrm{~cm}$ diameter, Rheonova). The gap was set at $1.5 \mathrm{~mm}$ and the temperature was $37^{\circ} \mathrm{C}$. The gel was prepared in situ within the geometry: the hot solution was injected between the plates and the measurement started after 15 minutes of setting. By preparing the gels directly within the rheometer gap, the gels kept a good contact with the plates and did not undergo synaeresis during the measurement at low sinusoidal strain. The gels were fast-cooled: slow cooling was not possible because of the water evaporation in the open rheometer geometry. To avoid the drying of the gel during the setting time and measurement, a ring of water droplets and a cover were placed around the geometry. After opening the geometry, the gels were homogeneous and white throughout the surfaces, but denser points corresponding to nucleation points were however visible. The elastic modulus G' and viscous modulus G" were recorded as a function of the frequency from 10 to $0.01 \mathrm{~Hz}$, with a sinusoidal strain amplitude of $0,2 \%$. The linear viscoelastic region was determined by a strain sweep from 0.5 to $10 \%$ (SI-5).

Uniaxial compression tests. Cylinders of gels were prepared in plastic molds (half cylinders, diameter $14 \mathrm{~mm}$, height $20 \mathrm{~mm}$, sealed with wax and metal rings). The hot solutions (1wt\% for Gal-C6; $0.45 \mathrm{wt} \%$ for Gal-C7; 0.5wt\% for Gal-C8) were dispensed in pre-heated molds. They were closed with a sealing foil and then cooled from $100^{\circ} \mathrm{C}$ to $25^{\circ} \mathrm{C}$ within 90 minutes. After cooling, the gels were gently removed from the molds, measured with a vernier calliper. All samples underwent uniaxial compression tests with Bose Electroforce 3100 mechanical testing machine equipped with a $20 \mathrm{~N}$ loading cell. Two compressive rates were applied: $5 \mathrm{~mm} / \mathrm{s}$ and $0.1 \mathrm{~mm} / \mathrm{s}$, up to $10 \%$ strain (SI-6, Figures S7-S8-S9). During compression, droplets of water are expelled from the gel cylinder that go back into the gel upon unloading. All tests have been made in triplicate. The curves from the first loading were fitted with polynomes. The first order terms of the polynomes were extracted and the mean of the three triplicates provided the initial modulus " $\mathrm{Y}_{0}$ " (first regime). The second regime modulus was determined from the tangent to the curves at higher strain (typically from 0.05 to 0.09 ).

\section{Cell culture, Cell viability assay and MTT based cell growth determination.}

The neuronal cell line (Neuro2A, ATCC) was cultured in Dulbecco's modified Eagle medium (DMEM) supplemented with $10 \%$ foetal bovine serum (FBS), and $1 \%$ penicillin-streptomycin at $37^{\circ} \mathrm{C}$ in a humidified atmosphere containing $5 \% \mathrm{CO}_{2}$.

For the cell viability assay, $300 \mu \mathrm{l}$ of the different gel compounds were prepared in an 8-well chamber slide (Lab-Tek, Nunc). After complete gelation, two extensive washes of several hours (4-5h and overnight) with $400 \mu \mathrm{l}$ of supplemented medium were performed. 30000 cells per well were seeded and cultured for 7 days. Fluorescent live-dead staining assay (Molecular probe) was used, according to the manufacturer instructions, to visualize the proportion of viable cells in green (calcein AM) and non-viable cells in red (ethidium homodimer-1). The samples were observed using a Zeiss Axioskop microscope equipped with a Cool SNAPfx camera (Photometrics). Each experiment was done at least in triplicate. Cell viability was evaluated by cell counting (live cells in green and dead cells in red). Three different fields for three independent experiments were analyzed for each gel condition using 
Image J Cell Counter. The percentage of cell viability was evaluated in each condition and results were expressed as the average $+/-\mathrm{SD}$ ).

For cell growth determination, $400 \mu \mathrm{l}$ of the different compounds were allowed to gel in each well of a 48 well plates (CellStar, Greiner Bio-One). After complete gelation with or without controlled cooling rate, two extensive washes of several hours (4-5h and overnight) with $600 \mu \mathrm{l}$ of supplemented medium were performed. Neuro2A cells were then seeded at a density of 35000 or 70000 per well, in $350 \mu \mathrm{l}$ of DMEM, and cultured for 1 or 4 days without changing medium to avoid cell lost. As controls, 35000 cells were directly seeded on the plastic well (2D control) corresponding to a culture which reaches confluence after 4 days. MTT based colorimetric test quantification (Sigma-Aldrich, France) were adapted for cell culture on gel. Briefly, after the determined culture period ( 1 or 4 days), $75 \mu \mathrm{l}$ of "MTT SOLUTION" (10\% of the total volume corresponding at the gel with the culture medium) were added to each well and allowed to react for 4 hours at $37{ }^{\circ} \mathrm{C}$. The culture medium was then carefully removed and $400 \mu \mathrm{l}$ of "MTT SOLVENT" were added in the wells, which enabled the gels to dissolve as well, to ensure a confident reading of the optical density. The absorbance was then measured spectrophotometrically at $570 \mathrm{~nm}$. The background absorbance was measured at $690 \mathrm{~nm}$. The absorbance of the gel alone was then subtracted to the obtained optical densities. Values were normalized to the $2 \mathrm{D}$ control. Three independent experiments were at least performed for each gel sample tested.

\section{Neuro2A-GFP and 3D confocal study}

Neuro2A cell line stably expressing the GFP protein were generated by transduction of the pLVBCpGfree-hCMV/hFerL-GFP lentiviral vector (generous gift from InvivoGen) using $1.0 \times 10^{6}$ infective units $/ \mathrm{ml}$ with polybrene $(4 \mu \mathrm{g} / \mathrm{ml})$ for $1.0 \times 10^{5}$ Neuro2A cell seeded in a 24 well plate. Positive clones were selected by subculture using a fluorescent microscope.

For 3D confocal microscopy observations, Neuro2A-GFP cells were seeded on a gel prepared in an 8well chamber slide with controlled cooling rate as describe above (90 minutes). In some experiments, a solution of laminin $(10 \mu \mathrm{g} / \mathrm{mL})$ was added during the last washing step for gel coating. However, no clear difference was observed between gels with (Figure 6) or without laminin (SI-8). After 5 days of culture, samples were fixed by addition of $4 \%$ paraformaldehyde solution for 30 min, washed with PBS, and then observed with a Leica SP8 confocal microscope. Gel fibers were imaged in parallel by confocal reflection microscopy. Images were captured using a x25 lens. 3D images were then reconstructed using Imaris Software.

\section{hNSC cell culture}

Biopsies from the temporal lobe and SVZ were obtained from individuals undergoing neurosurgery for epilepsy treatment $(n=3)$. All procedures were performed with informed patient consent, in accordance with our local human ethics committee (Comité de Protection des Personnes Sud-Ouest Outre Mer Toulouse I) and with institutional guidelines on human tissue handling and use. To isolate potential neural progenitor/stem cells, cell suspensions were rapidly obtained by tissue enzymatic digestion with trypsin $(65 \mu \mathrm{g} / \mathrm{ml}$, Sigma-Aldrich), hyaluronidase $(1.4 \mathrm{mg} / \mathrm{ml}$, Sigma Aldrich) and kyruneic acid $\left(0.2 \mathrm{mg} / \mathrm{ml}\right.$, Sigma-Aldrich) in DMEM/F12 with $5 \%$ glucose as already described ${ }^{51}$. Cells were then amplified as neurospheres in non-adherent conditions in DMEM/F12 medium containing B27 supplements (Gibco, Life technology), EGF (20ng/ml, Gibco, Life technology), bFGF (20ng/ml, Gibco, Life technology) and $1 \%$ penicillin-streptomycin. At the end of the amplification phase, the neurospheres were dissociated to obtain single-cell suspensions ${ }^{51}$ and seeded on Gal-C7 hydrogel in a 8 well chamber slide (Millipore) at a cell density of 75000 cells/well in DMEM/F12 medium with B27 supplements and NGF $(20 \mathrm{ng} / \mathrm{ml}$, Peprotech). Cell viability assay was realized after 7 days of culture as described above. Alternatively, immunostaining experiment was performed to study stem cell differentiation. Gels were pre-coated or not with laminin $(10 \mu \mathrm{g} / \mathrm{ml})$ but in this case also, laminin does not seem also to impact cell behavior on the gel. 


\section{hNSC immunostaining}

After 7 days of culture, samples were fixed by addition of $4 \%$ paraformaldehyde solution. To preserve the structure during the immunostaining procedure, samples (Gal-C7 gel with hNSC) were embedded in acrylamide gel with a protocol adapted from "CLARITY"60. A fresh solution containing: $0.6 \mathrm{~mL}$ of PBS $\times 10,4.65 \mathrm{~mL}$ of pure water, $0.6 \mathrm{~mL}$ of a $40 \%$ acrylamide solution and $0.15 \mathrm{~mL}$ of a $2 \%$ bisacrylamide solution and $15 \mathrm{mg}$ VA-044 (2,2'-Azobis[2-(2-imidazolin-2-yl)propane] dihydrochloride) was prepared in a sealed vial at $0^{\circ} \mathrm{C}$ and flushed with argon for $30 \mathrm{~min}$. After removing the supernatant, $300 \mu \mathrm{L}$ of the acrylamide solution was added in each well and kept for $45 \mathrm{~min}$ at $4^{\circ} \mathrm{C}$. This step was performed three times. The supernatant was again removed and the chamber slide was flushed with argon for $30 \mathrm{~min}$ at room temperature, then heated under argon at $43^{\circ} \mathrm{C}$ for 2 hours. After polymerization, PBS was added in each well and samples kept at $4^{\circ} \mathrm{C}$. For immunostaining procedure, the samples were washed 3 times for 45 min with $300 \mu$ of PB per well. The samples were then permeabilized with $0.1 \%$ Triton X-100 (Sigma-Aldrich) in PB for $30 \mathrm{~min}$ at room temperature, washed twice for 45 min with $\mathrm{PB}$, and incubated with a blocking solution ( $3 \%$ goat serum, DAKO) for $1 \mathrm{~h}$ at room temperature under shacking. Samples were then allowed to react with primary antibodies using the appropriate dilution of mouse anti-Tuj1 (1:500, Sigma-Aldrich) or rabbit anti-GFAP (1:1000, DAKO), for 24 hours at room temperature under shacking. After PB washes (twice, $45 \mathrm{~min}$ ), the appropriate secondary antibody (Alexa Fluor 488 anti-Mouse or -Rabbit, Molecular Probes), was incubated for $5 \mathrm{~h}$ under shaking. After 3 additional extensive PB washes, the samples were observed by confocal microscopy as described above.

\section{Statistical analyses}

MTT data and Nucleation point data are presented as means \pm standard deviations. Statistical analyses were performed, with GraphPad Prism v7.0 software, using a two-way ANOVA corrected for multiple comparisons by Bonferroni's test. For length and width fibers, data are represented as the median with interquartile ranges [first quartile: Q1; third quartile: Q3] for each group. Data were analyzed using the nonparametric Kruskal-Wallis test followed by the Dunn's multiple comparisons test as post hoc analyses. Results were considered significant for corrected $p$ values below 0.05 and are indicated by asterisks.

\section{Acknowledgments}

Stéphanie Bosch and Brice Ronsin (confocal microscopy, plateforme d'imagerie CBI-LITC constitutive de TRI (Toulouse Réseau d'Imagerie)); Bruno Payré, Isabelle Fourquaux, Dominique Goudounèche (TEM and cryo-TEM, Centre de Microscopie Electronique Appliquée à la Biologie, CMEAB); Xavier Dollat (LAAS); Delphine Bordignon (IMRCP); Pierre Roblin (SAXS, Fermat Platform, Toulouse); Caroline Toppan, Pierre Lavedan (NMR platform, Institut de Chimie de Toulouse, ICT Toulouse); Cyrille Rebout (ATG, LCC, Toulouse); Stéphane Gineste (DSC, IMRCP); Fabien Mesnilgrente (LAAS); Clément Roux (IMRCP) and Childérick SEVERAC (ITAV) for helpful discussions; Emmanuel Ravet (InvivoGen, for kind gift of lentiviral vectors). The French National Research Agency (ANR Neuraxe) is greatly acknowledged for A.C grant financial and financial support. The European Union is acknowledged for its financial support for equipment (FEDER-35477: "Nano-objets pour la biotechnologie").

\section{Author contributions}

L.V., A.C, J.-C.S. performed biology related experiments; A.C, J.F, S.S, B.L. performed gel related experiments; A.C., L.V., J.F., B.L. analyzed data; J.F., L.V., A.C., I.L., L.M., P.J., J.-C. S. designed research and J.F., L.V., A.C., P.J., L.M., I.L., B.L. wrote the paper.

Declarations of interest: The authors declare no conflict of interest.

Supporting information: synthesis and chemical characterization, fibers width distribution, SAXS analysis, rheology, stress-strain curves, viability on heterogeneous gels, 3D confocal stacks, N-pentyl- 
D-galactonamide and N-nonyl-D-galactonamide synthesis and gelation, thermogravimetric analysis, and 3D confocal microscopy video.

\section{References}

(1) Ravi, M.; Paramesh, V.; Kaviya, S. r.; Anuradha, E.; Solomon, F. D. P. 3D Cell Culture Systems: Advantages and Applications. J. Cell. Physiol. 2015, 230 (1), 16-26.

(2) Knight, E.; Przyborski, S. Advances in 3D Cell Culture Technologies Enabling Tissue-like Structures to Be Created in Vitro. J. Anat. 2015, 227 (6), 746-756.

(3) Edmondson, R.; Broglie, J. J.; Adcock, A. F.; Yang, L. Three-Dimensional Cell Culture Systems and Their Applications in Drug Discovery and Cell-Based Biosensors. ASSAY Drug Dev. Technol. 2014, 12 (4), 207-218.

(4) Murphy, A. R.; Laslett, A.; O'Brien, C. M.; Cameron, N. R. Scaffolds for 3D in Vitro Culture of Neural Lineage Cells. Acta Biomater. 2017.

(5) Collins, M. N.; Birkinshaw, C. Hyaluronic Acid Based Scaffolds for Tissue Engineering-A Review. Carbohydr. Polym. 2013, 92 (2), 1262-1279.

(6) Farrell, K.; Joshi, J.; Kothapalli, C. R. Injectable Uncrosslinked Biomimetic Hydrogels as Candidate Scaffolds for Neural Stem Cell Delivery. J. Biomed. Mater. Res. A 2017, 105 (3), 790805.

(7) Kaneko, A.; Matsushita, A.; Sankai, Y. A 3D Nanofibrous Hydrogel and Collagen Sponge Scaffold Promotes Locomotor Functional Recovery, Spinal Repair, and Neuronal Regeneration after Complete Transection of the Spinal Cord in Adult Rats. Biomed. Mater. 2015, 10 (1), 015008.

(8) Du, J.; Tan, E.; Kim, H. J.; Zhang, A.; Bhattacharya, R.; Yarema, K. J. Comparative Evaluation of Chitosan, Cellulose Acetate, and Polyethersulfone Nanofiber Scaffolds for Neural Differentiation. Carbohydr. Polym. 2014, 99, 483-490.

(9) Palm, T.; Bolognin, S.; Meiser, J.; Nickels, S.; Träger, C.; Meilenbrock, R.-L.; Brockhaus, J.; Schreitmüller, M.; Missler, M.; Schwamborn, J. C. Rapid and Robust Generation of Long-Term Self-Renewing Human Neural Stem Cells with the Ability to Generate Mature Astroglia. Sci. Rep. 2015, 5 (1).

(10) Sur, S.; Pashuck, E. T.; Guler, M. O.; Ito, M.; Stupp, S. I.; Launey, T. A Hybrid Nanofiber Matrix to Control the Survival and Maturation of Brain Neurons. Biomaterials 2012, 33 (2), 545-555.

(11) Tang-Schomer, M. D.; White, J. D.; Tien, L. W.; Schmitt, L. I.; Valentin, T. M.; Graziano, D. J.; Hopkins, A. M.; Omenetto, F. G.; Haydon, P. G.; Kaplan, D. L. Bioengineered Functional Brainlike Cortical Tissue. Proc. Natl. Acad. Sci. 2014, 111 (38), 13811-13816.

(12) Kim, Y. H.; Choi, S. H.; D’Avanzo, C.; Hebisch, M.; Sliwinski, C.; Bylykbashi, E.; Washicosky, K. J.; Klee, J. B.; Brüstle, O.; Tanzi, R. E.; Kim, D. Y. A 3D Human Neural Cell Culture System for Modeling Alzheimer's Disease. Nat. Protoc. 2015, 10 (7), 985-1006.

(13) Choi, S. H.; Kim, Y. H.; Hebisch, M.; Sliwinski, C.; Lee, S.; D’Avanzo, C.; Chen, H.; Hooli, B.; Asselin, C.; Muffat, J.; Klee, J. B.; Zhang, C.; Wainger, B. J.; Peitz, M.; Kovacs, D. M.; Woolf, C. J.; Wagner, S. L.; Tanzi; R. E.; Kim, D. Y. A Three-Dimensional Human Neural Cell Culture Model of Alzheimer's Disease. Nature 2014, 515 (7526), 274-278.

(14) Lancaster, M. A.; Renner, M.; Martin, C.-A.; Wenzel, D.; Bicknell, L. S.; Hurles, M. E.; Homfray, T.; Penninger, J. M.; Jackson, A. P.; Knoblich, J. A. Cerebral Organoids Model Human Brain Development and Microcephaly. Nature 2013, 501 (7467), 373-379.

(15) Thonhoff, J. R.; Lou, D. I.; Jordan, P. M.; Zhao, X.; Wu, P. Compatibility of Human Fetal Neural Stem Cells with Hydrogel Biomaterials in Vitro. Brain Res. 2008, 1187, 42-51.

(16) Ylä-Outinen, L.; Joki, T.; Varjola, M.; Skottman, H.; Narkilahti, S. Three-dimensional Growth Matrix for Human Embryonic Stem Cell-derived Neuronal Cells. J. Tissue Eng. Regen. Med. 2014, 8 (3), 186-194. 
(17) Kaneko, A.; Sankai, Y. Long-Term Culture of Rat Hippocampal Neurons at Low Density in Serum-Free Medium: Combination of the Sandwich Culture Technique with the ThreeDimensional Nanofibrous Hydrogel PuraMatrix. PLOS ONE 2014, 9 (7), e102703.

(18) Li, X.; Katsanevakis, E.; Liu, X.; Zhang, N.; Wen, X. Engineering Neural Stem Cell Fates with Hydrogel Design for Central Nervous System Regeneration. Prog. Polym. Sci. 2012, 37 (8), $1105-1129$.

(19) Chiono, V.; Tonda-Turo, C. Trends in the Design of Nerve Guidance Channels in Peripheral Nerve Tissue Engineering. Prog. Neurobiol. 2015, 131, 87-104.

(20) Guvendiren, M.; Molde, J.; Soares, R. M. D.; Kohn, J. Designing Biomaterials for 3D Printing. ACS Biomater. Sci. Eng. 2016, 2 (10), 1679-1693.

(21) Pati, F.; Gantelius, J.; Svahn, H. A. 3D Bioprinting of Tissue/Organ Models. Angew. Chem. Int. Ed. 2016, 55 (15), 4650-4665.

(22) Saha, K.; Keung, A. J.; Irwin, E. F.; Li, Y.; Little, L.; Schaffer, D. V.; Healy, K. E. Substrate Modulus Directs Neural Stem Cell Behavior. Biophys. J. 2008, 95 (9), 4426-4438.

(23) Leipzig, N. D.; Shoichet, M. S. The Effect of Substrate Stiffness on Adult Neural Stem Cell Behavior. Biomaterials 2009, 30 (36), 6867-6878.

(24) Sun, Y.; Yong, K. M. A.; Villa-Diaz, L. G.; Zhang, X.; Chen, W.; Philson, R.; Weng, S.; Xu, H.; Krebsbach, P. H.; Fu, J. Hippo/YAP-Mediated Rigidity-Dependent Motor Neuron Differentiation of Human Pluripotent Stem Cells. Nat. Mater. 2014, 13 (6), 599-604.

(25) Keung, A. J.; Asuri, P.; Kumar, S.; Schaffer, D. V. Soft Microenvironments Promote the Early Neurogenic Differentiation but Not Self-Renewal of Human Pluripotent Stem Cells. Integr. Biol. 2012, 4 (9), 1049.

(26) Keung, A. J.; Dong, M.; Schaffer, D. V.; Kumar, S. Pan-Neuronal Maturation but Not Neuronal Subtype Differentiation of Adult Neural Stem Cells Is Mechanosensitive. Sci. Rep. 2013, 3.

(27) Budday, S.; Sommer, G.; Birkl, C.; Langkammer, C.; Haybaeck, J.; Kohnert, J.; Bauer, M.; Paulsen, F.; Steinmann, P.; Kuhl, E.; Holzapfel, G. A. Mechanical Characterization of Human Brain Tissue. Acta Biomater. 2017, 48, 319-340.

(28) Zhou, J.; Li, J.; Du, X.; Xu, B. Supramolecular Biofunctional Materials. Biomaterials 2017, 129, $1-27$.

(29) Skilling, K. J.; Citossi, F.; Bradshaw, T. D.; Ashford, M.; Kellam, B.; Marlow, M. Insights into Low Molecular Mass Organic Gelators: A Focus on Drug Delivery and Tissue Engineering Applications. Soft Matter 2014, 10 (2), 237-256.

(30) Du, X.; Zhou, J.; Shi, J.; Xu, B. Supramolecular Hydrogelators and Hydrogels: From Soft Matter to Molecular Biomaterials. Chem. Rev. 2015, 115 (24), 13165-13307.

(31) Dou, X.-Q.; Feng, C.-L. Amino Acids and Peptide-Based Supramolecular Hydrogels for ThreeDimensional Cell Culture. Adv. Mater. 2017, 1604062.

(32) Webber, M. J.; Appel, E. A.; Meijer, E. W.; Langer, R. Supramolecular Biomaterials. Nat. Mater. 2015, 15 (1), 13-26.

(33) Berns, E. J.; Sur, S.; Pan, L.; Goldberger, J. E.; Suresh, S.; Zhang, S.; Kessler, J. A.; Stupp, S. I. Aligned Neurite Outgrowth and Directed Cell Migration in Self-Assembled Monodomain Gels. Biomaterials 2013.

(34) Lukyanova, L.; Franceschi-Messant, S.; Vicendo, P.; Perez, E.; Rico-Lattes, I.; Weinkamer, R. Preparation and Evaluation of Microporous Organogel Scaffolds for Cell Viability and Proliferation. Colloids Surf. B Biointerfaces 2010, 79 (1), 105-112.

(35) Clemente, M. J.; Romero, P.; Serrano, J. L.; Fitremann, J.; Oriol, L. Supramolecular Hydrogels Based on Glycoamphiphiles: Effect of the Disaccharide Polar Head. Chem. Mater. 2012, 24 (20), 3847-3858.

(36) Clemente, M. J.; Fitremann, J.; Mauzac, M.; Serrano, J. L.; Oriol, L. Synthesis and Characterization of Maltose-Based Amphiphiles as Supramolecular Hydrogelators. Langmuir 2011, 27 (24), 15236-15247.

(37) Ohsedo, Y.; Oono, M.; Saruhashi, K.; Watanabe, H. N-Alkylamido-Glucamine-Based Gelators for the Generation of Thixotropic Gels. RSC Adv. 2014, 4 (89), 48554-48558. 
(38) Fitremann, J.; Lonetti, B.; Fratini, E.; Fabing, I.; Payré, B.; Boulé, C.; Loubinoux, I.; Vaysse, L.; Oriol, L. A Shear-Induced Network of Aligned Wormlike Micelles in a Sugar-Based Molecular Gel. From Gelation to Biocompatibility Assays. J. Colloid Interface Sci. 2017, 504, 721-730.

(39) Tamaru, S.; Ikeda, M.; Shimidzu, Y.; Matsumoto, S.; Takeuchi, S.; Hamachi, I. Fluidic Supramolecular Nano- and Microfibres as Molecular Rails for Regulated Movement of Nanosubstances. Nat. Commun. 2010, 1, 20.

(40) Datta, S.; Bhattacharya, S. Multifarious Facets of Sugar-Derived Molecular Gels: Molecular Features, Mechanisms of Self-Assembly and Emerging Applications. Chem. Soc. Rev. 2015, 44 (15), 5596-5637.

(41) Latxague, L.; Ramin, M. A.; Appavoo, A.; Berto, P.; Maisani, M.; Ehret, C.; Chassande, O.; Barthélémy, P. Control of Stem-Cell Behavior by Fine Tuning the Supramolecular Assemblies of Low-Molecular-Weight Gelators. Angew. Chem. Int. Ed. 2015, 54 (15), 4517-4521.

(42) Ziane, S.; Schlaubitz, S.; Miraux, S.; Patwa, A.; Lalande, C.; Bilem, I.; Lepreux, S.; Rousseau, B.; Le Meins, J.-F.; Latxague, L.; Barthélémy, P.; Chassande, O. A Thermosensitive Low Molecular Weight Hydrogel as Scaffold for Tissue Engineering. Eur. Cell. Mater. 2012, 23, 147-160.

(43) Ramin, M. A.; Latxague, L.; Sindhu, K. R.; Chassande, O.; Barthélémy, P. Low Molecular Weight Hydrogels Derived from Urea Based-Bolaamphiphiles as New Injectable Biomaterials. Biomaterials 2017, 145 (Supplement C), 72-80.

(44) Yuan, D.; Du, X.; Shi, J.; Zhou, N.; Baoum, A. A.; Xu, B. Synthesis of Novel Conjugates of a Saccharide, Amino Acids, Nucleobase and the Evaluation of Their Cell Compatibility. Beilstein J. Org. Chem. 2014, 10, 2406-2413.

(45) Wang, W.; Wang, H.; Ren, C.; Wang, J.; Tan, M.; Shen, J.; Yang, Z.; Wang, P. G.; Wang, L. A Saccharide-Based Supramolecular Hydrogel for Cell Culture. Carbohydr. Res. 2011, 346 (8), 1013-1017.

(46) Xiao, X.; Hu, J.; Wang, X.; Huang, L.; Chen, Y.; Wang, W.; Li, J.; Zhang, Y. A Dual-Functional Supramolecular Hydrogel Based on a Spiropyran-galactose Conjugate for Target-Mediated and Light-Controlled Delivery of MicroRNA into Cells. Chem. Commun. 2016, 52 (84), 1251712520.

(47) Pfannemüller, B.; Welte, W. Amphiphilic Properties of Synthetic Glycolipids Based on Amide Linkages. I. Electron Microscopic Studies on Aqueous Gels. Chem. Phys. Lipids 1985, 37 (3), 227-240.

(48) Fuhrhop, J. H.; Schnieder, P.; Boekema, E.; Helfrich, W. Lipid Bilayer Fibers from Diastereomeric and Enantiomeric N-Octylaldonamides. J. Am. Chem. Soc. 1988, 110 (9), 28612867.

(49) Buerkle, L. E.; Galleguillos, R.; Rowan, S. J. Nonionic Surfactant-Induced Stabilization and Tailorability of Sugar-Amphiphile Hydrogels. Soft Matter 2011, 7 (15), 6984.

(50) Mizrahi, S.; Rizkov, D.; Hayat, N.; Lev, O. A Low Molecular Weight Hydrogel Which Exhibits Electroosmotic Flow and Its Use as a Bioreactor and for Electrochromatography of Neutral Species. Chem. Commun. 2008, No. 25, 2914.

(51) Vaysse, L.; Labie, C.; Canolle, B.; Jozan, S.; Beduer, A.; Arnauduc, F.; Vieu, C.; Sol, J. C.; Loubinoux, I. Adult Human Progenitor Cells from the Temporal Lobe: Another Source of Neuronal Cells. Brain Inj. 2012, 26 (13-14), 1636-1645.

(52) Vaysse, L.; Beduer, A.; Sol, J. C.; Vieu, C.; Loubinoux, I. Micropatterned Bioimplant with Guided Neuronal Cells to Promote Tissue Reconstruction and Improve Functional Recovery after Primary Motor Cortex Insult. Biomaterials 2015, 58, 46-53.

(53) Yuan, B.; Liu, X.-Y.; Li, J.-L.; Xu, H.-Y. Volume Confinement Induced Microstructural Transitions and Property Enhancements of Supramolecular Soft Materials. Soft Matter 2011, 7 (5), 17081713.

(54) Cui, J.; Liu, A.; Guan, Y.; Zheng, J.; Shen, Z.; Wan, X. Tuning the Helicity of Self-Assembled Structure of a Sugar-Based Organogelator by the Proper Choice of Cooling Rate. Langmuir 2010, 26 (5), 3615-3622. 
(55) Svenson, S.; Kirste, B.; Fuhrhop, J.-H. A CPMAS 13C NMR Study of Molecular Conformations and Disorder of N-Octylhexonamides in Microcrystals and Supramolecular Assemblies. J. Am. Chem. Soc. 1994, 116 (26), 11969-11975.

(56) Fernandez, R. M.; Riske, K. A.; Amaral, L. Q.; Itri, R.; Lamy, M. T. Influence of Salt on the Structure of DMPG Studied by SAXS and Optical Microscopy. Biochim. Biophys. Acta BBA Biomembr. 2008, 1778 (4), 907-916.

(57) Gibson, L. J.; Ashby, M. F. The Mechanics of Three-Dimensional Cellular Materials. Proc. R. Soc. Math. Phys. Eng. Sci. 1982, 382 (1782), 43-59.

(58) Kim, O. V.; Liang, X.; Litvinov, R. I.; Weisel, J. W.; Alber, M. S.; Purohit, P. K. Foam-like Compression Behavior of Fibrin Networks. Biomech. Model. Mechanobiol. 2016, 15 (1), $213-$ 228.

(59) Kim, O. V.; Litvinov, R. I.; Weisel, J. W.; Alber, M. S. Structural Basis for the Nonlinear Mechanics of Fibrin Networks under Compression. Biomaterials 2014, 35 (25), 6739-6749.

(60) Chung, K.; Deisseroth, K. CLARITY for Mapping the Nervous System. Nat. Methods 2013, 10 (6), 508-513.

(61) Greim, H.; Bury, D.; Klimisch, H. J.; Oeben-Negele, M.; Ziegler-Skylakakis, K. Toxicity of Aliphatic Amines: Structure-Activity Relationship. Chemosphere 1998, 36 (2), 271-295.

(62) Kuang, Y.; Xu, B. Disruption of the Dynamics of Microtubules and Selective Inhibition of Glioblastoma Cells by Nanofibers of Small Hydrophobic Molecules. Angew. Chem. Int. Ed. 2013, 52 (27), 6944-6948.

(63) Petkova, A. T. Self-Propagating, Molecular-Level Polymorphism in Alzheimer's -Amyloid Fibrils. Science 2005, 307 (5707), 262-265.

(64) Gotoh, N.; Moroda, K.; Watanabe, H.; Yoshinaga, K.; Tanaka, M.; Mizobe, H.; Ichioka, K.; Tokairin, S.; Wada, S. Metabolism of Odd-Numbered Fatty Acids and Even-Numbered Fatty Acids in Mouse. J. Oleo Sci. 2008, 57 (5), 293-299.

(65) Shimizu, T.; Masuda, M. Stereochemical Effect of Even-Odd Connecting Links on Supramolecular Assemblies Made of 1-Glucosamide Bolaamphiphiles. J. Am. Chem. Soc. 1997, 119 (12), 2812-2818.

(66) Liu, G.-F.; Zhang, D.; Feng, C.-L. Control of Three-Dimensional Cell Adhesion by the Chirality of Nanofibers in Hydrogels. Angew. Chem. Int. Ed. 2014, 53 (30), 7789-7793.

(67) Wong, J. Y.; Leach, J. B.; Brown, X. Q. Balance of Chemistry, Topography, and Mechanics at the Cell-biomaterial Interface: Issues and Challenges for Assessing the Role of Substrate Mechanics on Cell Response. Surf. Sci. 2004, 570 (1-2), 119-133.

(68) Béduer, A.; Vieu, C.; Arnauduc, F.; Sol, J.-C.; Loubinoux, I.; Vaysse, L. Engineering of Adult Human Neural Stem Cells Differentiation through Surface Micropatterning. Biomaterials 2012, 33 (2), 504-514. 